\title{
Professional Networks and their Coevolution with Executives' Careers: Evidence from Europe and the US
}

\author{
Nicoletta Berardi ${ }^{a b}$ and Paul Seabright ${ }^{a c}$ \\ a: Toulouse School of Economics \\ b: Banque de France \\ c: Institute for Advanced Studies in Toulouse, Centre for Economic Policy Research
}

\begin{abstract}
This paper examines how networks of professional contacts contribute to the development of the careers of executives of European and US companies. We build a dynamic model of career progression in which career moves both depend upon existing networks and contribute to the development of future networks. We test the theory on an original dataset of nearly 6000 executives in over 3000 firms. We find evidence that professional networks are relevant both because valuable for the employer and because they facilitate job mobility. Our estimates of the elasticity of executives' salaries with respect to the size of their professional networks vary between around $6 \%$ and around $26 \%$ depending on the specification, with a point estimate under our preferred specification of $7.6 \%$.
\end{abstract}

JEL classification: D85; J31; J62.

Keywords: social network; labor mobility; top management compensation.

We thank Sebastian Kohls and Marie Lalanne for extremely helpful collaboration and participants at Bicocca and CREST seminar at at AFSE and EEA conference. We are also grateful to Sanvi Avouyi-Dovi, Roberto Berardi, Guido Friebel, Matthew O. Jackson, Jean-Yves Lesueur, Patrick Sevestre, and Gregory Verdugo for helpful comments. We wish to thank as well Richard Taylor, Victoria Derkach and Irina Waibel for assistance with the BoardEx database. The views expressed in this paper are those of the authors and do not necessarily represent those of their institutions.

* Corresponding author: Banque de France, 31 rue Croix des Petits Champs, 75001 Paris, France.

E-mail: Nicoletta.Berardi@banque-france.fr 


\section{Introduction}

How do networks of professional contacts contribute to the development of an individual's career? In particular, do they do so by making the individual more valuable to an employer, or rather by overcoming information asymmetries and enabling the individual to take advantage of employment opportunities he or she might otherwise not hear about? In this paper we explore this question empirically using a sample of executives in US and European firms.

Careers are shaped by a succession of professional opportunities and mobility decisions. Career developments are often relatively smooth, entailing gradual promotions or changes of responsibilities and duties within the current firm. However, at several points in time opportunities may arise that would modify the ex ante direction, like junctions in a road network. These represent discontinuous jumps in the career trajectory, and each decision whether or not to change job affects a worker's future offers.

What characterizes career progression is its dynamic dimension: choices at each switching point affect subsequent decisions. What's more, each choice influences the opportunities that will arise in the future both directly and indirectly. Indeed, not only do the type of offers potentially available at each point in time depends on one's current and past jobs, but crucially the probability of receiving an offer may be also affected by one's professional previous history through the characteristics of the network that each worker builds in her professional environment. In turn, when a worker decides to change job, her network is affected, so that professional network and career actually coevolve.

Our approach in this paper is to build a dynamic model of career progression and to test it on an original dataset of nearly 6000 executives and board members in over 3000 firms in 4 countries (US, UK, France, and Germany) between 1997 and 2009! The richness of the dataset allows to account for the dynamic aspects of the relationship between professional networks and career progression, exploiting the panel dimension of the dataset.

Our econometric analysis focuses on the effects of the professional network on salary. Based on the benchmark specification suggested by our theoretical framework, we find that professional networks are relevant both because they are valuable for the employer and because they

\footnotetext{
${ }^{1}$ The dataset is based on information provided by BoardEx Ltd.
} 
facilitate job mobility. These findings are robust to alternative definitions of career value and specifications accounting for mobility and link endogeneity. Moreover, networks characterized on average by ties between nodes that have been colleagues for a long time have a lower direct and indirect effect on labor outcomes, corroborating the well known arguments of Granovetter [1973] about 'the strength of weak ties'. Finally, the older are the links in an individual's network, the less valuable they are to the employer.

This paper is structured as follows. Section 2 reviews the literature. Section 3 describes our data and gives a number of descriptive statistics. Section 4 develops a theoretical model of an individual's dynamic career choices. Section 5 derives the econometric specification and presents the results. Section 6 concludes.

\section{Literature review}

The literature on social networks has been growing very rapidly in recent years, both in sociology and more recently in economics. The boom in network research has been seen as part of a general shift, beginning in the second half of the $20^{\text {th }}$ century, away from individualist, essentialist and atomistic explanations toward more relational, contextual and systemic understandings.

Labor market outcomes are among the most carefully studied examples of the importance of networks in economics. Granovetter [1973]'s pioneering work on the strength of weak ties drew attention to the significance of networks for employment. Indeed, networks represent crucial conduits spreading the awareness of new vacancies. Moreover, they further increase the probability of getting a job by reducing the imperfect information of employers about employee characteristics. In particular, a well-established literature argues that they reduce selection concerns and improve the quality of matching on unobservable characteristics (see Montgomery [1991], Saloner [1985] and Simon and Warner [1992]). Berardi [2010] shows that they also reduce moral hazard, since a social network may monitor and exert pressure on a worker that was hired through it. Indeed, empirical evidence shows that the use of social networks as hiring channel is widespread. Granovetter [1973, Rees [1966] and Corcoran [1980] found that about half of the jobs in the United States were filled through personal contacts and Ioannides and Loury 2004] have shown that the role played by networks has increased over time. 
Beyond employment, people access career opportunities, like job promotions, through friends, colleagues, and other contacts. In the words of Burt 1992]: "Criteria other than financial and human capital are used to narrow the pool down to the individual who gets the opportunity. Those other criteria are social capital. New life is given to the proverb of success being determined less by what you know than by who you know". This sense of the term 'social capital' is entirely consistent with the coinage of the term by Coleman [1988] [2]

Networks not only affect the probability of getting a job or a promotion, but they are also likely to have an impact on wages in a given job. However, there is no consensus as to the sign of the effect. Montgomery [1991], Simon and Warner 1992, Kugler 2003], and Ioannides and Soetevent 2006] among others find higher wage rates on average, while for instance Pistaferri [1999] and Bentolila et al. 2010] find lower wages, when the position is filled through social networks. Berardi 2010] develops a theoretical model rationalizing positive or negative wage differentials, depending on the circumstances in terms of network tightness, cultural context, non-monetary gains, bargaining power and occupation.

The characteristics of individual networks are crucial in determining the effects on labor outcomes. Network size is the primary measure. Munshi 2003] shows that social interactions improve labor market outcomes among migrants and, in particular, that a larger network at the destination substantially increases the probability that the individual will be employed. Similarly, Beaman [2012], Conley and Topa 2002, and Bayer et al. [2008] find that a larger network helps in job search. Patacchini and Zenou [2008], based on the dynamic model of Calvó-Armengol and Jackson [2004], stress that the individual probability of finding a job is increasing in the number of ties. Using a panel of local authority-level data in England between 1993 and 2003, they find that the higher the percentage of a given ethnic group living nearby, the higher the employment rate of this ethnic group. Podolny and Baron [1997] find that mobility is enhanced by having large networks for those informal ties oriented toward acquiring information and resources. Finally, Burt [1992 argues that size is a mixed blessing. More contacts can mean more exposure to valuable information, more likely early exposure, and more referrals. However, increasing network size without considering its diversification can be

\footnotetext{
${ }^{2}$ Indeed he states that "An important form of social capital is the potential for information that inheres in social relations"
} 
costly without bringing much benefit. Indeed, social contacts require time and energy and new links that make a network denser can simply fatten it without expanding it.

The relation between network size and expected wages has generally been found to be positive on average (see Arrow and Borzekowski 2004, Montgomery 1991, and Boxman et al. [1991]). Ioannides and Soetevent [2006] find that the wage rates of the most well connected are $15 \%$ to $25 \%$ higher than those of workers without connections. ${ }^{3}$

Other aspects of networks may matter apart from their size. Munshi [2003] also shows that a longer-established network at the destination substantially increases the probability that a migrant will be employed. Podolny and Baron [1997] instead stress that the effects of tie duration on mobility vary across types of networks. In particular, they distinguish between ties that are position-based or induced by organizational structure and those that are person-based or discretionary. The mobility benefit of networks that are primarily position-based should be shorter-lived than the value of person-based ties; the former will tend to obsolesce with time, especially after an individual changes formal positions, whereas the latter, being based on trust and familiarity, should appreciate with time!

The strength of weak ties argument affirmed by Granovetter [1973] stresses the prominent role of weak ties as far as labor outcomes are concerned. Recent contributions by Berardi [2010] and Patacchini and Zenou 2008] show that the role played by tightness may vary with circumstances. A complementary approach initiated by Burt [1992] argues that what matters the most is not tightness, but the number of non redundant contacts $\stackrel{5}{[}$ People bridging structural holes ${ }^{6}$ should know about more rewarding opportunities and obtain higher rates of return.

This paper bridges between the network literature and the rather vast literature on executive board members' compensation and mobility. It is particularly important to draw together the insights of these two fields, since professional networks are often used in the recruitment

$3^{3}$ Lalanne and Seabright 2011] find that this relation holds only for men executives; better connected women executives do not have salaries significantly higher than less well connected women.

${ }^{4}$ Podolny and Baron [1997] reckon that in the organizational context many ties function primarily as conduits for some resource, particularly access and information. However, they stress that ties in a cohesive social group are important sources of identity and social support, which may be as well crucial in a professional context, for instance allowing to internalize clear expectations for one's role.

${ }^{5}$ Burt 1992 argues that, while weak ties and structural holes seem to describe the same phenomenon, the causal agent in the phenomenon is not the weakness of a tie but the structural hole it spans and the weak-tie argument obscures the control benefits of structural holes.

[Burt 1992 defines a structural hole as a relationship of non redundancy between two contacts. Thus, non redundant contacts are connected by a structural hole. 
of executives. Indeed, such individuals constitute "a tiny group of about a dozen individuals holding unusual power in overseeing a company's future and corporations make all efforts to recruit well-connected and experienced directors. (...) This interlocked network of board members plays a crucial role in spreading corporate practices and maintaining the political and economic clout of big corporations" (Barabási [2002]).

At the same time, "the managerial labor market offers a unique and data-rich environment to analyze promotions, separations, and careers. Even when results for executives cannot be easily extrapolated to other labor groups, the results are important in their own right: top managers are critical and highly visible inputs into the corporate production function, and understanding better their role can enrich our understanding of both incentives and organizations" (Murphy [1999]).

Finally, executive compensation has attracted much attention since the 90s, particularly due to growing disparities between CEO pay and average worker pay ${ }^{1}$ [Engelberg et al. [2012] and Brown et al. 2009] show CEOs' networks have a sizable effect on their compensation. This paper focuses instead on the role of the professional network on executives' salary and mobility.

\section{Dataset and stylized facts}

The analysis is based on an original dataset describing the career history of more than 50000 executives and board members of US, UK, French and German companies between 1997 and 2009 8 The dataset was provided to us by BoardEx Ltd, a UK supplier of data to headhunting companies. BoardEx's own proprietary database (which we refer to hereafter as the 'main' database) consists of information about some 380000 individuals who are current or past board members or executives of European and US companies. The database provided to us, however, consists of the subset of their main database ${ }^{9}$ for which salary data are available at least for some years between 1997 and 2009. There are about 4000 firms in our dataset, and for each firm

\footnotetext{
${ }^{7}$ The rapid growth in executives' pay started in the mid-1970s and has been observed to decline only after 2000 (Frydman and Jenter 2010).

${ }^{8}$ Notice that the panel is very unbalanced. The average number of workers that are present in the dataset in one year is about 30000 and the average number of years a worker is present is less than 5 .

${ }^{9}$ BoardEx cut-off criterion is a market capitalization above 1 million USD.For UK and US BoardEx has a complete coverage on companies listed on major indices. Our dataset is composed of individuals working for firms randomly drawn from BoardEx coverage. We end up with 2100 firms based in the US, 1613 in the UK, and the full BoardEx coverage of France (220) and Germany (80).
} 
we have information about all board members; for firms with fewer than five board members we have information on the five most highly salaried executives where salary information exists. The dataset contains information about individuals' demographic characteristics such as age and gender, about individuals' employment history such as earnings and position, about individuals' education characteristics such as degree achieved and major, and about firms' characteristics such as sector or number of employees.

Our analysis discards individuals that hold a board position with no executive responsibilities (about half of the overall original dataset)!10 This choice is motivated by the fact that nonexecutives have very different compensation schemes from executives, often composed of a null or symbolic salary component, and usually hold a position in many boards at the same time 11 Moreover, since the transition between executive and non-executive positions $\frac{12}{12}$ entails specific salary dynamics, we focus on workers that keep executive positions over time $\frac{13}{13}$ We also exclude individuals with null salary, since this is highly unlikely to result from a proper executive occupation. Finally, since the main focus of this paper is on job mobility and very few executives change job each year, our econometric analysis relies on a cumulation of job changes over 4 year (about 5\% of executives changed firm, whether voluntarily or involuntarily, between 2002 and 2006) and on a cross-section enriched with lagged values referring to 4 years before. Finally, we put aside the first years of data due to relatively low coverage, and the last three years due to the crisis period. The benchmark analysis of this paper is based on data referring to the years 2006 and lagged values of 2002 14 Table 1 and 2 show some descriptive statistics at the individual and firm level respectively for the year 2006.

The unique feature of our dataset is the information provided on networks. In general, each individual is simultaneously embedded in very different types of social networks. In the present context we are especially interested in the professional network, that is, the links resulting from

\footnotetext{
${ }^{10}$ Lalanne and Seabright 2011] document that executives and non-executives behave in very different ways.

${ }^{11}$ The most frequent categories of executive jobs are CEOs. The main functions held are general management, followed by finance. Notice that executives may also hold a seat on a board. Our analysis focuses however on their main executive position.

${ }^{12}$ Vancil (1987) estimates that $80 \%$ of exiting (non-deceased) CEOs remain on their firms' boards of directors; and $36 \%$ continue serving on the board as chairman.

${ }^{13}$ Among workers holding an executive position in 2006 and also present in the dataset in $2002,4 \%$ were not holding an executive position in 2002. This may imply a small bias in our selected sample.

${ }^{14}$ The time period 2002-2006 has the highest number of observations and is obviously not affected by the crisis. We also undertook the same analysis on 2007 data with no qualitative change in the results (available upon request).
} 
Table 1: Descriptive statistics at the individual level for executives in 2006.

\begin{tabular}{llllll}
\hline \hline Variable & Mean & (SD) & Min. & Max. & N \\
\hline Number of links & 147.444 & $(196.175)$ & 6 & 1669 & 5898 \\
Mean link duration (years) & 5.036 & $(2.138)$ & 1.7 & 16.667 & 5898 \\
Mean link age (years) & 5.876 & $(4.762)$ & 0 & 38.465 & 5898 \\
Colleagues in network & 15.157 & $(65.777)$ & 1 & 3575 & 5915 \\
Salary (thousands USD) & 390 & $(291)$ & 1.7 & 6919 & 5915 \\
Liquid wealth (thousands USD) & 34507 & $(700535)$ & 0 & 42684792 & 5681 \\
Total wealth (thousands USD) & 43302 & $(727428)$ & 0 & 42684792 & 4371 \\
Changed firm voluntarily or not since 2005 (prop) & 0.019 & $(0.137)$ & 0 & 1 & 4450 \\
Changed firm voluntarily or not since 2002 (prop) & 0.049 & $(0.215)$ & 0 & 1 & 4450 \\
Gender: female (prop) & 0.049 & $(0.216)$ & 0 & 1 & 5915 \\
Age & 53.371 & $(7.499)$ & 32 & 97 & 5892 \\
Achieved degree: BA (prop) & 0.214 & $(0.41)$ & 0 & 1 & 5915 \\
Achieved degree: MA (prop) & 0.275 & $(0.447)$ & 0 & 1 & 5915 \\
Achieved degree: PhD (prop) & 0.167 & $(0.373)$ & 0 & 1 & 5915 \\
Degree major: Business (prop) & 0.235 & $(0.424)$ & 0 & 1 & 5915 \\
Degree major: Finance (prop) & 0.069 & $(0.254)$ & 0 & 1 & 5915 \\
Degree major: Science (prop) & 0.016 & $(0.124)$ & 0 & 1 & 5915 \\
Degree major: Social Science (prop) & 0.074 & $(0.262)$ & 0 & 1 & 5915 \\
\hline
\end{tabular}

Table 2: Descriptive statistics at the firm level for 2006.

\begin{tabular}{llllll}
\hline \hline \multicolumn{1}{c}{ Variable } & Mean & (SD) & Min. & Max. & N \\
\hline Firm number of employees & 13436 & $(48218)$ & 1 & 1800000 & 3178 \\
Firm country: US (prop) & 0.556 & $(0.497)$ & 0 & 1 & 3260 \\
Firm country: UK (prop) & 0.382 & $(0.486)$ & 0 & 1 & 3260 \\
Firm country: France (prop) & 0.042 & $(0.2)$ & 0 & 1 & 3260 \\
Firm country: Germany (prop) & 0.020 & $(0.141)$ & 0 & 1 & 3260 \\
Sector: construction (prop) & 0.033 & $(0.18)$ & 0 & 1 & 3260 \\
Sector: defense (prop) & 0.009 & $(0.096)$ & 0 & 1 & 3260 \\
Sector: education (prop) & 0.002 & $(0.043)$ & 0 & 1 & 3260 \\
Sector: financial (prop) & 0.128 & $(0.334)$ & 0 & 1 & 3260 \\
Sector: health (prop) & 0.03 & $(0.172)$ & 0 & 1 & 3260 \\
Sector: information (prop) & 0.152 & $(0.359)$ & 0 & 1 & 3260 \\
Sector: mining (prop) & 0.071 & $(0.257)$ & 0 & 1 & 3260 \\
Sector: real estate (prop) & 0.042 & $(0.201)$ & 0 & 1 & 3260 \\
Sector: services (prop) & 0.091 & $(0.288)$ & 0 & 1 & 3260 \\
Sector: technical (prop) & 0.047 & $(0.212)$ & 0 & 1 & 3260 \\
Sector: trade (prop) & 0.061 & $(0.24)$ & 0 & 1 & 3260 \\
Sector: transportation (prop) & 0.031 & $(0.174)$ & 0 & 1 & 3260 \\
Sector: utilities (prop) & 0.032 & $(0.177)$ & 0 & 1 & 3260 \\
\hline
\end{tabular}


one's professional activity. There are many ways of assessing networks. Often people are asked to list their links. This procedure suffers however from concerns related to self-reporting and directionality of the reported ties. Moreover, it is very costly and therefore usually identifies rather small and intimate networks. Here instead, links are factual 15 , not revealed. In our dataset a link is created when two persons work together ${ }^{16}$ The average number of professional links is 147 , while the median is 72 in $2006 \frac{17}{17}$ what follows we use the variable name 'Links' to refer to the number of members of the BoardEx main database with whom an individual in our dataset has worked in the same firm at the same time. This is the main explanatory variable we shall use in the analysis that follows. Notice that the links are not necessarily to other individuals in our dataset, which would arbitrarily restrict our measure of the size of individuals' networks by whether or not we have salary information about the members of that network.

Also note that, even if one of the two nodes leaves the workplace, the link is not considered extinct. However, the link with a past colleague may play a different role than an ongoing relationship with a colleague. Therefore, we compute the number of years elapsed since two workers have been colleagues. The mean link 'age' is almost 6 years, while the median is 4 and a half. We also compute the number of contemporaneous colleagues present in the dataset, which is on average about 15. Finally, we calculate the 'duration' of a link as the years of overlapping of two persons in the same workplace. The mean overlap is about 5 years.

Most executive pay packages contain four components: a base salary, an annual bonus tied to accounting performance, stock options, and long-term incentive plans. In our dataset salary

\footnotetext{
${ }^{15}$ Links are defined on the basis of relational states and events. That is, social ties are proxied by group comembership, which is likely to contribute to the formation of ties. While in general it is difficult to infer whether people know each other at work, in the case of top executives it seems unlikely that two of them working in the same firm do not know each other one way or another. However, we lack information about the effort invested in each potential link.

${ }^{16}$ While many studies focus on friends, the focus of this paper is on professional links. Indeed, Podolny and Baron 1997. find that friendship is not the relevant network for studying career mobility. Cingano and Rosolia 2012 use the same notion of professional network that we adopt. Notice that the network of all contacts acquired while working would be larger than the professional network of current and previous colleagues defined in this paper.

${ }^{17}$ Extrapolating from the brain sizes and social networks of apes, Dr.Dunbar suggested that the size of the human brain allows stable networks of about 150, which is known as the Dunbar number. Other anthropologists have come up with estimates of almost double the Dunbar number for the upper limit of human groups. Sociologists distinguish between a person's wider network of people known by name, estimate between 200 and 5000 , and his social core.
} 
is base annual pay. Liquid wealth is the sum of the value of shares held $\frac{18}{18}$ and the intrinsic value of exercisable options 19 . Finally, total wealth is the sum of equity, estimated value of options, and long term incentive programs held (in thousand of US Dollars). This paper focuses on salary. Indeed, executives devote substantial attention to the salary-determination process. Although salaries comprise a declining percentage of total compensation, 20 they are key in the contract and risk free. Moreover, most components of compensation are measured relative to base salary levels! $\frac{21}{1}$ Wealth on the other hand is more likely to be reported with measurement error, since it is often difficult to assess it precisely. In a robustness analysis we look at wealth; network effects are qualitatively similar, but stronger $\stackrel{22}{2}$, consistently with the results reported in Engelberg et al. 2012] and in Lalanne and Seabright 2011.

The probability of changing organization between 2005 and 2006 is less than $2 \%$ on average 23 Only $5 \%$ of executives are women and the average age is 53 years. They often hold a master degree in Business. Finally, Table 2 shows some characteristics at the firm level, such as size and sector. The majority of firms have their headquarters in the US and the most common sectors in the dataset are finance, information, and services.

A first exploration of the variables that are at the center of this paper (professional links, salary, and mobility decisions $\sqrt{24}$ reveals some interesting patterns 25 that are going to form the basis of the theoretical framework of the paper. Figure 1 shows the median salary in 2006 (left hand axis) and the average proportion of executives who changed firm, whether voluntarily or involuntarily, between 2002 and 2006 (right hand axis) by quartiles of the size of their

\footnotetext{
${ }^{18}$ That is, multiplies the number of shares held directly by the individual by the stock price of the organization.

${ }^{19}$ That is, by how much the total number of options held are in the money. This is the gap between the exercise price of the options held and the stock price, multiplied by the number of options held.

${ }^{20}$ The increase over time of executive pay is mainly attributable to increase in the grant-date value of stock option grants, but the growth in stock option use did not occur at the expense of other components of pay (see Murphy [1999] and Frydman and Jenter 2010]).

${ }^{21}$ See Murphy 1999.

${ }^{22}$ See section 5.3 .1 .

${ }^{23}$ The mean time spent in an organization almost 14 years. Among executives $60 \%$ are also board members and the average number of years spent in a board is below 2 years. Jensen and Murphy 1990] find in a thirteen-year sample that CEOs hold their jobs an average of over ten years before leaving, and most leave their position only after reaching normal retirement age. $60 \%$ of their sample CEOs are between 60 and 66 when they leave their firm; $32 \%$ are ages 64 or 65 .

${ }^{24}$ As already explained, we look at variables in 2006 and use 2002 as previous period when considering lagged values.

${ }^{25}$ These relations and their significance are robust to a first set of ceteris paribus analyses (results available upon request) that includes a number of controls at the individual (previous salary, age, gender, degree level and major) and firm (country, sector, and size) level.
} 
median salary (2006) $\quad$ mean proportion of executives who changed firm (2002-2006)

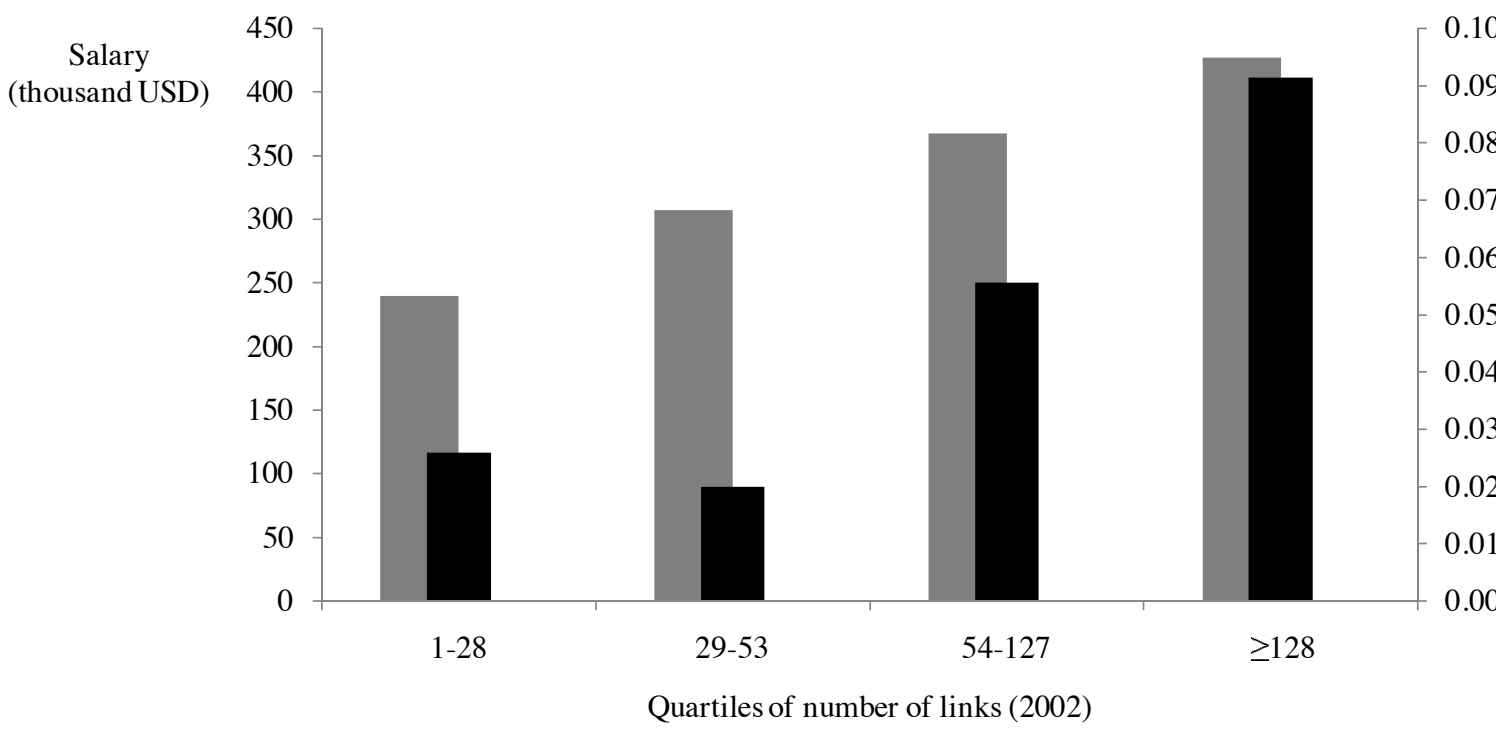

Changed firm

09 (proportion)

0.08

0.07

0.06

0.05

0.04

0.03

0.02

0.01

00

Figure 1: Salary and mobility by quartile of network size.

professional network in 2002. Salary monotonically increases with network size and executives with the most professional links earn almost twice the salary of those with the least links. Similarly, the proportion of executives who changed firm voluntarily or involuntarily between 2002 and 2006 also increases with network size in 2002 26 Indeed, the Spearman correlation between salary and previous professional links is significant and equal to 0.33. At the same time, the Wilcoxon-Mann-Whitney test $\stackrel{27}{ }$ indicates that the salary significantly differs between workers that stayed in the same firm and those who decided to change firm in the previous four years. In particular, the former have lower salaries than the latter on average. Moreover, mobility decisions significantly vary with professional links. Indeed, the size of the professional network of workers deciding to stay is smaller than for people changing firm in the subsequent period. Finally, the number of professional links is larger for workers that previously decided to change firm and it is strongly related to the number of links previously held, as expected.

Therefore, the modeling exercise developed in section 4 is going to take into account the following observations: 1) salary is significantly related to previous number of professional links and mobility; 2) mobility is related to the size of the professional network contemporaneous to

\footnotetext{
${ }^{26}$ Mobility is slightly higher among executives with the least links than for the second quartile. This may result from workers with fewer links being more likely to leave the firm involuntarily.

${ }^{27}$ The Wilcoxon-Mann-Whitney test is a non-parametric test for independent samples.
} 
the decision; 3) the number of links is related to both the number of previously held links and to previous mobility decisions.

\section{Theoretical framework}

The key idea underlying our modeling of career dynamics is that career choices and professional networks coevolve. We develop a dynamic framework where the utility of a worker is affected by the choices she makes during her career and by the characteristics of her professional network. The idea is that wages may be directly affected by professional networks if their characteristics are valuable for the employer. Indeed, the fact that an employee has personal contacts with workers in another firm may increase the likelihood of new contracts or facilitate the transactions between the two firms. An alternative interpretation, even if contacts did not improve business, is that they may affect the bargaining power of a worker $\frac{28}{2}$ The individuals' employment network outside the firm represents in this sense a form of social capital that may be useful for the employer and that is thus 'remunerated'. Decisions along the career path shape the development of one's professional network. For instance, when a worker decides to move to a new firm, her professional network is likely to expand, since new links will be created with new colleagues. Thus, mobility choices affect worker's network. At the same time it seems reasonable to argue that professional opportunities don't arise randomly among workers. A wellestablished stylized fact is that the probability of moving to another firm is likely to be affected by an individual's employment network. In particular, the larger the first degree network of the individual, the higher the probability that she gets exposed to job offers. This is particularly true in the case of top managers and board members. These positions are usually filled through head hunting and professional acquaintanceship, rather than through formal advertisement of openings.

\subsection{Setting}

An individual's career is modeled as a sequence of periods from $t=0, \ldots, T$. In $t=0$ the individual starts her career and at the end of $t=T$ she retires. At many points in time during

\footnotetext{
${ }^{28}$ This interpretation is explored for CEOs by Engelberg et al. [2012.
} 
an individual's career, each worker may have a choice whether or not to change her job. While professional dynamics may entail continuous progressions within the current firm and even within the current job position, this paper especially focuses on discrete progressions. Indeed, changing firm is usually the kind of professional mobility that most actively involves and affects an individual's professional network ${ }^{29}$ We thus simplify the space of career choices, restricting our attention to a worker's decision to accept an offer from another firm, as illustrated in Figure 2. Between the beginning and the end of the career, the individual may have the opportunity to

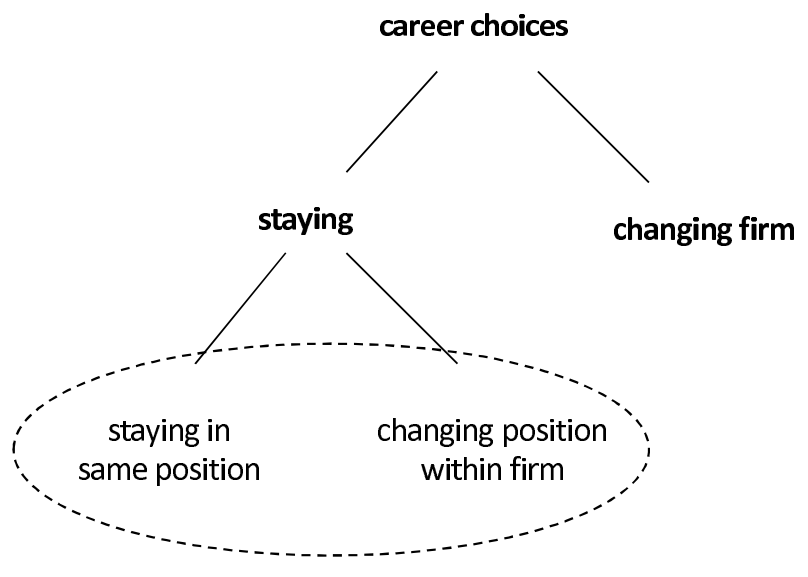

Figure 2: Potential career choices.

change firm several times. That is, at each time $0 \leq t<T$, she may receive news of opportunities in an alternative firm. In this case, she evaluates the best outside option and compare it with the continuation in the current firm. In $t+1$ she will either still work in current firm or will have changed firm.

We begin by ignoring uncertainty for the moment. The individual maximizes the sum of the discounted utility during her whole career:

$$
V_{1}\left(l_{0}\right)=\max _{\left\{a_{t}\right\}_{t=0}^{T-1}} \sum_{t=0}^{T-1} \gamma^{t} U_{t+1}\left(l_{t}, a_{t}\right)
$$

subject to $a_{t} \in\left\{S\left(l_{t}\right), M\left(l_{t}\right)\right\}$ and $l_{t+1}=\varphi\left(l_{t}, a_{t}\right) \forall t=0, \ldots, T-1$, where $\gamma$ is the discount factor, $l_{t}$ are the characteristics of the relevant employment network and $a_{t}$ is the decision to stay $(S)$ or move $(M)$ in $t$, which affects utility in $t+1$. Intuitively, a worker's utility depends

\footnotetext{
${ }^{29}$ Another crucial reason why this paper restricts attention to mobility across firms is that from an empirical point of view it is possible to identify with more precision this type of mobility than promotions within a firm.
} 
on mobility choices and the probability of changing job may depend on a worker's professional network, if the information about new job opportunities spreads through it. Moreover, professional links may directly affect utility if their characteristics are valuable to the employer and are thus remunerated as part of wage $\stackrel{30}{30}$ Finally, the decision of staying or moving in $t$ will in turn affect the shape of her professional network in $t+1$.

Bellman's Principle of Optimality suggests that the maximization can be rewritten as:

$$
V_{1}\left(l_{0}\right)=\max _{a_{0}} U_{1}\left(l_{0}, a_{0}\right)+\gamma\left[\max _{\left\{a_{t}\right\}_{t=1}^{T-1}} \sum_{t=1}^{T-1} \gamma^{t-1} U_{t+1}\left(l_{t}, a_{t}\right)\right]
$$

subject to $a_{0} \in\left\{S\left(l_{0}\right), M\left(l_{0}\right)\right\}, l_{1}=\varphi\left(l_{0}, a_{0}\right)$, and $a_{t} \in\left\{S\left(l_{t}\right), M\left(l_{t}\right)\right\}, l_{t+1}=\varphi\left(l_{t}, a_{t}\right)$ $\forall t=1, \ldots, T-1$.

The optimal value that can be obtained is therefore:

$$
V_{1}\left(l_{0}\right)=\max _{a_{0}}\left[U_{1}\left(l_{0}, a_{0}\right)+\gamma V_{2}\left(l_{1}\right)\right]
$$

subject to $a_{0} \in\left\{S\left(l_{0}\right), M\left(l_{0}\right)\right\}$ and $l_{1}=\varphi\left(l_{0}, a_{0}\right)$. In the case where time is infinite we could drop time subscripts and write $V(l)=\max _{a \in\{S(l), M(l)\}}[U(l, a)+\gamma V(\varphi(l, a))]$

In fact an individual's career horizon is finite so the maximization problem is solved backward starting from the last period of career.

In fact also, uncertainty matters to individual choices since not all possibilities are available for sure. We assume that the individual can always choose to stay in the current firm with probability one. While not strictly realistic, this allows us to ignore firing or firm bankruptcy and focus on voluntary career moves. The decision taken in $t$ whether or not to change job in $t+1$ arises with the probability $p\left(l_{t}\right)$, which is an increasing function of the number of professional ties in $t$. Thus, in $t$ the expected value is:

$$
\mathbb{E} V_{t+1}\left(l_{t}\right)=p\left(l_{t}\right) \max _{a_{t}}\left[V_{t+1}\left(l_{t} \mid a_{t}=S\right), V_{t+1}\left(l_{t} \mid a_{t}=M\right)\right]+\left[1-p\left(l_{t}\right)\right] V_{t+1}\left(l_{t} \mid a_{t}=S\right)
$$

We further assume that there always exists a potential offer that gives at least the value provided

\footnotetext{
${ }^{30}$ Notice the value to the employer of an employee's professional network that it is possible to identify does not correspond in a non-neoclassical framework to the total value that a worker represent to her employer. Rather, by 'value to the employer' we mean the value that the employer is induced to bid for an employee at equilibrium.
} 
by staying in the current firm, i.e. $V_{t+1}\left(l_{t} \mid a_{t}=M\right) \geq V_{t+1}\left(l_{t} \mid a_{t}=S\right)$. In this case, $p\left(l_{t}\right)$ represents the probability that a job opportunity better than the current one arises and the expected value simplifies to:

$$
\mathbb{E} V_{t+1}\left(l_{t}\right)=p\left(l_{t}\right) V_{t+1}\left(l_{t} \mid a_{t}=M\right)+\left(1-p\left(l_{t}\right)\right) V_{t+1}\left(l_{t} \mid a_{t}=S\right)
$$

where $V_{t+1}\left(l_{t} \mid a_{t}=S\right)=U_{t+1}\left(l_{t} \mid a_{t}=S\right)+\gamma \mathbb{E} V_{t+2}\left(l_{t+1} \mid a_{t}=S\right)$ and $V_{t+1}\left(l_{t} \mid a_{t}=M\right)=$ $U_{t+1}\left(l_{t} \mid a_{t}=M\right)+\gamma \mathbb{E} V_{t+2}\left(l_{t+1} \mid a_{t}=M\right)$.

The optimal value depends on current utility and expected future value. That is, when a worker is considering an offer to change job, she takes into account on one hand the proposed compensation, which may be directly affected by her professional network if the employer values it. On the other hand, she also takes into account the dynamic effect of moving, through the changes in her network. Indeed, changing jobs is likely to increase her professional network, which in turn will increase the probability of receiving interesting offers in the future (and, thus, the expected future value), so that network and career actually coevolve.

\subsection{The role of professional links}

We turn now to a more analytical understanding of the different channels whereby professional links affect career outcomes. From expression (1) it is easy to see that the professional network plays a role in several ways. Indeed, the derivative of the value in $t+1$ with respect to professional links in $t$ is:

$$
\begin{aligned}
& \frac{\partial \mathbb{E} V_{t+1}\left(l_{t}\right)}{\partial l_{t}}=\frac{\partial p\left(l_{t}\right)}{\partial l_{t}} {\left[V_{t+1}\left(l_{t} \mid a_{t}=M\right)-V_{t+1}\left(l_{t} \mid a_{t}=S\right)\right]+} \\
&+p\left(l_{t}\right)\left[\frac{\partial V_{t+1}\left(l_{t} \mid a_{t}=M\right)}{\partial l_{t}}-\frac{\partial V_{t+1}\left(l_{t} \mid a_{t}=S\right)}{\partial l_{t}}\right]+\frac{\partial V_{t+1}\left(l_{t} \mid a_{t}=S\right)}{\partial l_{t}}
\end{aligned}
$$

If we assume that the way links affect the value does not depend on mobility decisions 31

\footnotetext{
${ }^{31}$ If this hypothesis were not true, the same network would have a different effect depending on whether a worker changes firm or not. That is, the link direct effect would be different for stayers and movers. In this case, empirically we would need to allow for potentially different effects on links on the salary for movers and stayers. We should then estimate an endogenous switching model. However, since there are few observations for movers, convergence is not achieved. Therefore, to the extent that it is reasonable to assume that links have the same effect on salary for movers and for stayers, it is possible to interpret the difference in the impact of links on value for movers and stayers as a measure of the probability of moving.
} 
i.e. $\frac{\partial V_{t+1}\left(l_{t} \mid a_{t}=M\right)}{\partial l_{t}} \approx \frac{\partial V_{t+1}\left(l_{t} \mid a_{t}=S\right)}{\partial l_{t}}$, then expression (2) simplifies to:

$$
\frac{\partial \mathbb{E} V_{t+1}\left(l_{t}\right)}{\partial l_{t}}=\underbrace{\frac{\partial V_{t+1}\left(l_{t} \mid a_{t}=S\right)}{\partial l_{t}}}_{\text {link direct effect }}+\underbrace{\frac{\partial p\left(l_{t}\right)}{\partial l_{t}}}_{\text {link indirect effect }} \underbrace{\left[V_{t+1}\left(l_{t} \mid a_{t}=M\right)-V_{t+1}\left(l_{t} \mid a_{t}=S\right)\right]}_{\text {mobility effect }}
$$

Expression (3) implies that the overall impact of links results from three effects. The first term constitutes the direct effect that professional links have on value beyond mobility, that is, the extent to which they directly affect the career value. It captures the value that a worker's contacts represent to the employer. The second is a composite term capturing the role that professional networks play through mobility (i.e. second and third effect): the gain from changing job with respect to staying in the current firm multiplied by the extent to which links affect the probability of getting the information about a better job opportunity.

\subsection{From the theoretical framework to the empirical specification}

In order to assess the relative role played by the different effects that are identified in the theoretical framework, it is necessary to disentangle the three channels. Indeed, if we simply estimated $Y_{t+1}=\beta_{0}+\beta_{1} l_{t}+\beta_{2} X_{t+1}+\epsilon_{t+1}$, where $Y_{t+1}$ is the career value (for the moment, it can be useful to think of it as simply the salary) and $X_{t+1}$ the standard determinants, the estimated

coefficient $\widetilde{\beta_{1}}$ would combine the three channels whereby links affect a worker's value. Nor it is sufficient to include explicitly the mobility decisions (i.e., $Y_{t+1}=\beta_{0}+\beta_{1} l_{t}+\beta_{2} X_{t+1}+\beta_{3} A_{t}+\epsilon_{t+1}$, where $A_{t}$ is the decision taken in period $t$, or $\left.Y_{t+1}=\beta_{0}+\beta_{1} l_{t}+\beta_{2} X_{t+1}+\beta_{3} A_{t}+\beta_{4} l_{t} * A_{t}+\epsilon_{t+1}\right)$, since $A_{t}$ may be endogenous with respect to $Y_{t+1}$. Indeed, beyond professional networks, some unobserved individual or firm characteristics may affect both mobility and salary.

Instead, based on the theoretical framework the benchmark empirical specification in this paper takes into account that utility depends directly on links and on mobility decisions. Moreover, it considers that the professional network affects the probability of career mobility and therefore indirectly utility. That is, the benchmark empirical specification consists of two stages. The first stage estimates the probability of being offered a better job opportunity:

$$
A_{t}=\delta_{0}+\underbrace{\delta_{1}}_{\text {link indirect effect }} l_{t}+\delta_{2} Z_{t}+\zeta_{t}
$$


where $Z_{t}$ includes the controls $X_{t+1}$ and at least a mobility determinant that is legitimately excluded from the second stage. The second stage is then represented by:

$$
Y_{t+1}=\beta_{0}+\underbrace{\beta_{1}}_{\text {link direct ef fect }} l_{t}+\beta_{2} X_{t+1}+\underbrace{\beta_{3}}_{\text {mobility effect }} \widehat{A}_{t}+\epsilon_{t+1}
$$

The three components singled out in the theoretical framework (see expression (3) in section 4.2) correspond to the estimated coefficient $\widehat{\beta}_{1}$ (link direct effect), $\widehat{\beta_{3}}$ (mobility effect), and $\widehat{\delta_{1}}$ (link indirect effect).

In principle, the potential endogeneity of professional links with respect to salary is of course a concern. Rauch 2010] suggests that links created in firms are exogenous to some extent. However, the employment network evolves as agents leave their firms to join other firms. Consistently, our model explicitly accounts for the reciprocal causal relationship between mobility and network size: links in period $t$ may affect the mobility decision taken in that period and effective in $t+1$. Reverse causality is not an issue because we use lagged links and the impact of changing firm on network size will be realized in $t+1$. As for the residual possibility that unobserved individual characteristics affect both network size and salaries, we take this partially into account by the inclusion of lagged salaries. Lalanne and Seabright 2011] explore the issue of unobserved heterogeneity in detail using a dynamic panel analysis, an issue whose importance is stressed by Rauch [2010], and find that the magnitude of the effect of network size on salaries is slightly higher when estimated in this way than when unobserved heterogeneity is ignored or treated via a lagged dependent variable; this suggests that any bias in our own results is likely to be small and in the direction of strengthening our results $\frac{32}{32}$

Notice that in general $Y_{t+1}$ is not simply represented by the salary, but by the continuation value. One way to approximate the continuation value empirically is to take into account not only salary, but also equities, stock options, and long term incentive plans. However, the precision of this global amount is not very high. Therefore, beyond checking alternative measures of the dependent variable, we also run a further complementary test to check the robustness of the benchmark specification. The test is based on the observation that in the last

\footnotetext{
${ }^{32}$ We cannot use a dynamic panel analysis for our own specification because of the infrequency with which individuals change firms in any one year (an aspect Lalanne and Seabright 2011] do not explore).
} 
period of a worker's career $(T)$, she has no longer to decide whether changing job and links are then not useful to find a better job in the following period (i.e. $p\left(l_{T}\right)=0$ ) 33 Therefore, in period $T-1$ the continuation value simplifies to the utility and expression (3) can be rewritten as:

$$
\frac{\partial \mathbb{E} V_{T}\left(l_{T-1}\right)}{\partial l_{T-1}}=\frac{\partial U_{T}\left(l_{T-1} \mid a_{T-1}=S\right)}{\partial l_{T-1}}+\frac{\partial p\left(l_{T-1}\right)}{\partial l_{T-1}}\left[U_{T}\left(l_{T-1} \mid a_{T-1}=M\right)-U_{T}\left(l_{T-1} \mid a_{T-1}=S\right)\right]
$$

Thus, we can estimate link effects directly on salary for individuals close to retirement 34

\section{$5 \quad$ Econometric specification and results}

In the theoretical framework developed in section 4, at many points in time during a worker's career she may receive offers and has to decide whether to stay in the current firm or to change job. The decision taken at each point is dynamic and takes into account not only the utility in that period, but also the discounted expected utility in the future. In particular, the optimal value depends on professional networks directly through utility to the extent that links are valuable to the employer and indirectly through the effect that they have on mobility decisions.

Based on the benchmark specification suggested by the theoretical framework, we find evidence that professional networks are relevant both because valuable for the employer and because they facilitate job mobility. Moreover, we investigate some characteristics of the relevant network component (section 5.2). We find that contemporaneous colleagues are not useful channels of information transmission about job opportunities, nor valuable for the employer. The average length of the overlapping time of workers in the same firm and the average time elapsed since then have a negative impact on the network value to the employer. Moreover we find that professional networks characterized by longer average time spent in the same firm as colleagues are less useful to find a better job. To the extent that overlapping time may proxy ties strength, this result supports Granovetter's theory of the 'strength of weak ties'. Finally, we check the robustness of the main findings with respect to alternative definitions of career

\footnotetext{
${ }^{33}$ This seems reasonable as far as executive positions are concerned, while it may still be the case that the professional network built in an executive career contributes to getting a better non-executive position in a board. This is however beyond the dynamics analyzed by the present paper.

${ }^{34}$ The results can be generalized to the extent that the way networks affect utility does not change over time.
} 
value and to specifications accounting for mobility and link endogeneity (section 5.3.2). Table 11 summarizes the estimated elasticities of salary with respect to professional links.

\subsection{Benchmark}

The benchmark econometric specification suggested by the theoretical framework developed in section 4 comprises a first stage where the dependent variable is the mobility decision (see expression (4) in section 4.3) and a second stage where the dependent variable is the career value (see expression (5)). Since mobility decisions are endogenous to salary it is necessary that at least one variable included in $Z_{t}$ in expression (4) is legitimately excluded from the $X_{t+1}$ variables in expression (5).

In transposing the theoretical framework to empirical estimation we face the practical difficulty that the percentage of workers changing firm between each period $t$ and $t+1$ is extremely low if we consider a one-year interval. Therefore, four years are cumulated. The dependent variable of the first stage (from table 4 on) is a dummy variable taking unit value if a worker has changed firm between 2002 (excluded) and 2006 (included).

To be able to interpret the results on the basis of our framework, where dismissal is ruled out and mobility decisions result from the maximization of the expected value over the career, the econometric analyses that follow do not consider individuals that changed firm and get a lower salary as workers that voluntarily decided to work for another firm $\stackrel{35}{5}$ It is possible that workers may choose a job for unobservable reasons, but we cannot distinguish empirically between this voluntary choice and workers who were fired and find a job elsewhere. While this trimming could potentially create a bias, table 5 shows that the main results do not change.

Before proceeding to the estimation of our benchmark, we rapidly illustrate the simple OLS estimates for comparison purposes. The first column of table 3 shows the simplest possible OLS estimation. The estimated elasticity of salary with respect to professional links captures the overall impact of network size on salary. The estimated network effect implies that a $1 \%$ change in network size accompanies a $0.179 \%$ increase in salary on average. For instance, $50 \%$ more links (from the average of 122 to 183 ) would imply an average annual salary increase of 35 thousand USD (from the average 390 to 425 thousand USD). However, there may be

\footnotetext{
${ }^{35}$ Between 2002 and 2006 the percentage of executives changing firm without salary penalties is $66 \%$.
} 
some unobserved factors that affect both the number of professional links and salary. We therefore include as a control past salary (column [II]) in order to control as much as possible for unobserved heterogeneity. Taking into account mean reversion reduces the elasticity with respect to links by two thirds. Including past salary may actually lead to some underestimation of the effect of professional networks on salary by absorbing even too much variance related to individual heterogeneity. Alternative specifications are run in section 5.3 .3 and confirm that the network effect as estimated by our benchmark specification is likely to be quite conservative.

The theoretical framework points out that professional links may also affect salary through their impact on mobility. The third and fourth column of table 3 take into account the role played by mobility by including a dummy variable that takes unit value when a worker has changed job in the previous 4 years $\frac{36}{36}$ Column [IV] also controls for unobserved heterogeneity through past salary. However, as explained in section 4.3, it is not sufficient to include mobility as it may be endogenous. Therefore, we now turn to the estimation of our benchmark specification.

The benchmark specification results from our theoretical framework. The latter identified three effects of professional networks on the career value (see section 4.2): a link direct effect (beyond mobility), a mobility effect (the gain from changing firm), and a link indirect effect (through the probability of changing firm). The link direct and indirect effects correspond to the estimated coefficients of links respectively in the second and first stage $\left(\beta_{1}\right.$ in expression (5) and $\delta_{1}$ in expression (4) in section 4.3). The mobility effect is represented by the estimated coefficient of the dummy variable for having changed firm $\left(\beta_{3}\right.$ in expression (5) in section 4.3).

In order to be able to estimate the two-stage model, we need to single out factors that affect voluntary choices of changing job, but are not salary determinants otherwise. A natural candidate are external conditions that may affect mobility choices. For instance, to the extent that executives are able to work for firms in different sectors, they could be more inclined to change job when their sector suffers from an economic slowdown. We thus exploit the evolution of sectoral stock index, namely the MSCI sectoral weighted market capitalization index ${ }^{37}$, to

\footnotetext{
${ }^{36}$ Notice that once introduced this variable, the dummy variables for firm location in France and Germany are dropped due to collinearity. Indeed, there are no workers in firms located in France and Germany who changed firm between 2002 and 2006. This is not surprising, since firms in France and Germany represent respectively only $4 \%$ and $2 \%$ of sampled firms.

${ }^{37}$ We exploit the MSCI sectoral weighted market capitalization index relative to the US and Europe (for firms
} 
Table 3: Network effects on salary (OLS estimation).

\begin{tabular}{|c|c|c|c|c|}
\hline Ln salary (2006) & {$[\mathrm{I}]$} & [II] & [III] & {$[\mathrm{IV}]$} \\
\hline \multirow[t]{2}{*}{ Ln links (2002) } & $0.179^{* * *}$ & $0.060^{* * *}$ & $0.177^{* * *}$ & $0.055^{* * *}$ \\
\hline & $(0.01)$ & $(0.01)$ & $(0.01)$ & $(0.01)$ \\
\hline \multirow[t]{2}{*}{ Age (2006) } & $0.140^{* * *}$ & 0.014 & $0.163^{* * *}$ & 0.022 \\
\hline & $(0.02)$ & $(0.01)$ & $(0.02)$ & $(0.01)$ \\
\hline \multirow[t]{2}{*}{ Age sq. (2006) } & $-0.001^{* * *}$ & -0.000 & $-0.002^{* * *}$ & $-0.000^{*}$ \\
\hline & $(0.00)$ & $(0.00)$ & $(0.00)$ & $(0.00)$ \\
\hline \multirow[t]{2}{*}{ Gender: female } & $-0.199 * * *$ & -0.035 & $-0.226 * * *$ & -0.044 \\
\hline & $(0.05)$ & $(0.04)$ & $(0.06)$ & $(0.03)$ \\
\hline \multirow[t]{2}{*}{ Achieved degree: BA } & $0.189^{* * *}$ & $0.069 * * *$ & $0.181^{* * *}$ & $0.063^{* * *}$ \\
\hline & $(0.03)$ & $(0.02)$ & $(0.04)$ & $(0.02)$ \\
\hline \multirow[t]{2}{*}{ Achieved degree: MA } & $0.176^{* * *}$ & $0.080^{* * *}$ & $0.172^{* * *}$ & $0.080^{* * *}$ \\
\hline & $(0.04)$ & $(0.02)$ & $(0.04)$ & $(0.02)$ \\
\hline \multirow[t]{2}{*}{ Achieved degree: $\mathrm{PhD}$} & $0.145^{* * *}$ & 0.039 & $0.144^{* * *}$ & 0.026 \\
\hline & $(0.04)$ & $(0.03)$ & $(0.04)$ & $(0.03)$ \\
\hline \multirow[t]{2}{*}{ Degree major: Business } & $0.082^{* * *}$ & 0.028 & $0.108^{* * *}$ & 0.029 \\
\hline & $(0.03)$ & $(0.02)$ & $(0.03)$ & $(0.02)$ \\
\hline \multirow[t]{2}{*}{ Degree major: Finance } & -0.038 & 0.028 & -0.014 & 0.038 \\
\hline & $(0.04)$ & $(0.03)$ & $(0.04)$ & $(0.03)$ \\
\hline \multirow[t]{2}{*}{ Degree major: Science } & $-0.213^{* *}$ & $-0.104^{* *}$ & -0.085 & -0.022 \\
\hline & $(0.08)$ & $(0.05)$ & $(0.11)$ & $(0.07)$ \\
\hline \multirow[t]{2}{*}{ Degree major: Social Sciences } & 0.008 & 0.054 & -0.006 & 0.057 \\
\hline & $(0.05)$ & $(0.04)$ & $(0.06)$ & $(0.04)$ \\
\hline \multirow[t]{2}{*}{ Firm country (2006): UK } & $0.209^{* * *}$ & $0.260^{* * *}$ & $0.234^{* * *}$ & $0.264^{* * *}$ \\
\hline & $(0.03)$ & $(0.02)$ & $(0.03)$ & $(0.02)$ \\
\hline \multirow[t]{2}{*}{ Firm country (2006): Germany } & -0.117 & -0.211 & & \\
\hline & $(0.09)$ & $(0.27)$ & & \\
\hline \multirow[t]{2}{*}{ Firm country (2006): France } & $-0.447^{* * *}$ & 0.011 & & \\
\hline & $(0.12)$ & $(0.13)$ & & \\
\hline \multirow[t]{2}{*}{ Ln salary (2002) } & & $0.718^{* * *}$ & & $0.717^{* * *}$ \\
\hline & & $(0.02)$ & & $(0.02)$ \\
\hline \multirow[t]{2}{*}{ Changed firm (2002-06) } & & & 0.097 & $0.290 * * *$ \\
\hline & & & $(0.06)$ & $(0.08)$ \\
\hline \multirow[t]{2}{*}{ Intercept } & $1.027^{*}$ & $1.154^{* * *}$ & 0.611 & $1.017^{* * *}$ \\
\hline & $(0.58)$ & $(0.33)$ & $(0.62)$ & $(0.36)$ \\
\hline $\mathrm{N}$ & 5828 & 5771 & 4434 & 4434 \\
\hline$R^{2}$ & 0.129 & 0.616 & 0.137 & 0.632 \\
\hline
\end{tabular}

Note: Robust Standard Errors in brackets, clustered by firm.

Significance levels: *: $10 \% * *: 5 \% * * *: 1 \%$.

take into account the fact that a worker's choice to change job can result from poor growth in UK, Germany, and France). The index is a market capitalization weighted index that is designed to measure the equity market performance of the developed markets. 
of the industry she is working in. The growth rate of sectoral weighted market capitalization index between 2006 and 2002 corresponding to the firm where the worker was in $2002^{38}$ captures the evolution of the market capitalization index for the 'incumbent' sector. It is expected to have a negative impact on the probability of moving. For this sectoral performance variable to be a valid instrument, it is also necessary that it does not affect salary beyond its impact through mobility decisions. The determinants of salary are many and complex and it would seem possible that sectoral performance might correlate with compensation. However, sectoral growth tends to influence other components that are more variable than salary, if any, and indeed many studies looking for sectoral performance effects in executive compensation have not found any relation $\frac{39}{39}$

We also impose an additional exclusion restriction relying on a different source of external variation. The fact that a firm changed the country of its headquarters is likely to affect mobility choices of its workers, while not directly the salary component of their overall compensation 40 To the extent that the exclusion restrictions hold, the estimated coefficients of the benchmark specification reported in table 4 allow us to assess the multiple effect that professional networks have on workers' career.

The main object of interest in the first stage estimation is the relation between network size and mobility. Indeed, the estimated network coefficient relates to the indirect effect of links on salary through the probability of changing firm. The theoretical framework described in section 4 assumes that mobility decisions depend on a workers' professional network. In particular, we expect that the probability of receiving an interesting job offer is increasing in the number of direct links of an individual. As expected, in the first stage the number of professional links held before the mobility decision takes place significantly increases the probability of changing firm. The estimated marginal effect is 0.012 , suggesting that if the network increases by $50 \%$ (from the average 122 links to 183), the probability of choosing to change firm increases by $15 \%$ (from the average $3.2 \%$ to $3.7 \%$ ).

\footnotetext{
${ }^{38}$ This firm variable has a mean of 0.63 and a standard deviation of 0.22 . The minimum value is -0.06 and the maximum 1.24 .

${ }^{39}$ Jensen and Murphy [1990] for instance find that for CEOs that their compensation is unrelated to market and industry performance. Friebel and Matros 2005. provide a theoretical framework explaining how CEOs in bad firms may nonetheless receive larger wages.

${ }^{40}$ This is a rare event, taking place for only $1.3 \%$ of firms.
} 
Table 4: Network effects on salary (2SLS estimation: benchmark).

\begin{tabular}{lllll}
\hline \hline & \multicolumn{3}{c}{ [I stage] } & \multicolumn{2}{c}{ [II stage] } \\
& Changed firm $(2002-06)$ & Ln salary $(2006)$ \\
\hline Ln links (2002) & $0.019^{* * *}$ & $(0.00)$ & $0.076^{* * *}$ & $(0.01)$ \\
Ln salary (2002) & $-0.015^{* * *}$ & $(0.00)$ & $0.702^{* * *}$ & $(0.02)$ \\
Age (2006) & -0.000 & $(0.00)$ & 0.022 & $(0.02)$ \\
Age sq. (2006) & -0.000 & $(0.00)$ & $-0.000^{*}$ & $(0.00)$ \\
Gender: female & -0.011 & $(0.01)$ & -0.053 & $(0.03)$ \\
Achieved degree: BA & $0.014^{* *}$ & $(0.01)$ & $0.080^{* * *}$ & $(0.02)$ \\
Achieved degree: MA & $0.016^{*}$ & $(0.01)$ & $0.098^{* * *}$ & $(0.03)$ \\
Achieved degree: PhD & 0.009 & $(0.01)$ & 0.041 & $(0.03)$ \\
Degree major: Business & $0.018^{* *}$ & $(0.01)$ & $0.047^{*}$ & $(0.03)$ \\
Degree major: Finance & 0.012 & $(0.01)$ & 0.050 & $(0.03)$ \\
Degree major: Science & -0.010 & $(0.02)$ & -0.034 & $(0.07)$ \\
Degree major: Social Sciences & 0.003 & $(0.01)$ & 0.057 & $(0.05)$ \\
Firm country (2006): UK & $0.033^{* * *}$ & $(0.01)$ & $0.297^{* * *}$ & $(0.03)$ \\
Sectoral growth for 2002-firm $(2006-02)$ & $-0.026^{*}$ & $(0.01)$ & & \\
Headquarters country changed (2006-02) & $0.562^{* * *}$ & $(0.13)$ & & \\
Changed firm (2002-06) & & & -0.780 & $(0.50)$ \\
Intercept & 0.066 & $(0.08)$ & $1.056^{* * *}$ & $(0.40)$ \\
\hline N & 4434 & & 4434 & \\
Pseudo R ${ }^{2} / R^{2}$ & 0.063 & & 0.574 & \\
F statistic cluster-robust & 11.24 & & & \\
Hansen J statistic & & & & \\
Hansen J $\chi^{2}$ p-value & & & & \\
\hline \hline
\end{tabular}

Note: Robust Standard Errors in brackets, clustered by firm.

Significance levels: *: $10 \% * *$ : $5 \% * * *$ : $1 \%$.

The estimated coefficients reported in the first column of table 4 also suggest that the higher the previous salary, the lower the probability of changing job $\underline{41}$ This is consistent with the observation that the utility of staying in the current firm is likely to be a smoother evolution of the utility of previous period, while moving is more likely to be accompanied by utility jumps.

The second stage regression shows that the size of the professional network significantly affects salaries directly, even beyond its impact on mobility. The estimated coefficient of links suggests that a $50 \%$ increase in network size accompanies a $3.8 \%$ increase of salary with respect to the average. In other words, if a worker has $50 \%$ more links than the average (from 122 to 183 links), her annual salary would increase by 15 thousand USD (from an average of 390 to 405 thousand USD).

\footnotetext{
${ }^{41}$ Abowd et al. [2006] consistently find that firms that pay high wages have low turnover rate.
} 
Table 5: Network effects on salary (2SLS estimation: robustness in full sample).

\begin{tabular}{lllll}
\hline \hline & \multicolumn{3}{c}{ [I stage] } & \multicolumn{2}{c}{ [II stage] } \\
& Changed firm $(2002-06)$ & Ln salary $(2006)$ \\
\hline Ln links (2002) & $0.027^{* * *}$ & $(0.00)$ & $0.074^{* * *}$ & $(0.01)$ \\
Ln salary (2002) & -0.007 & $(0.00)$ & $0.710^{* * *}$ & $(0.02)$ \\
Age (2006) & -0.004 & $(0.00)$ & 0.020 & $(0.01)$ \\
Age sq. (2006) & 0.000 & $(0.00)$ & $-0.000^{*}$ & $(0.00)$ \\
Gender: female & -0.001 & $(0.02)$ & -0.045 & $(0.03)$ \\
Achieved degree: BA & 0.013 & $(0.01)$ & $0.077^{* * *}$ & $(0.02)$ \\
Achieved degree: MA & 0.014 & $(0.01)$ & $0.094^{* * * *}$ & $(0.02)$ \\
Achieved degree: PhD & 0.014 & $(0.01)$ & 0.041 & $(0.03)$ \\
Degree major: Business & $0.024^{* *}$ & $(0.01)$ & $0.045^{*}$ & $(0.02)$ \\
Degree major: Finance & 0.018 & $(0.01)$ & 0.049 & $(0.03)$ \\
Degree major: Science & -0.004 & $(0.02)$ & -0.029 & $(0.07)$ \\
Degree major: Social Sciences & -0.002 & $(0.01)$ & 0.053 & $(0.04)$ \\
Firm country (2006): UK & $0.044^{* * *}$ & $(0.01)$ & $0.295^{* * *}$ & $(0.02)$ \\
Sectoral growth for 2002-firm $(2006-02)$ & $-0.032^{*}$ & $(0.02)$ & & \\
Headquarters country changed (2006-02) & $0.873^{* * *}$ & $(0.07)$ & & \\
Changed firm or fired (2002-06) & & & $-0.513^{* *}$ & $(0.23)$ \\
Intercept & 0.111 & $(0.10)$ & $1.063^{* * *}$ & $(0.38)$ \\
\hline N & 4434 & & 4434 & \\
Pseudo R ${ }^{2} / R^{2}$ & 0.090 & & 0.622 & \\
F statistic cluster-robust & 84.00 & & & \\
Hansen J statistic & & & & \\
Hansen J $\chi^{2}$ p-value & & & & \\
\hline \hline
\end{tabular}

Note: Robust Standard Errors in brackets, clustered by firm.

Significance levels: *: $10 \% * *: 5 \% * * *: 1 \%$.

The second stage estimates also show that once the endogeneity of mobility is taken into account, we cannot reject the hypothesis that changing firm has no impact on salary, so that mobility per se does not significantly affect salary. In other terms, out of the three potential effects identified by the theoretical model (section 4.2) the indirect and direct effects of links are positive and significant, while the mobility effect is not significantly different from zero once considering endogeneity.

Mincerian determinants are, as expected, significant 4.42 Workers that earned a degree ${ }^{43}$ with a major in Business have on average higher salary and a higher probability of changing job than

\footnotetext{
${ }^{42}$ Murphy 1999 notices that Mincerian determinants may be less significant for top executive remuneration than for other jobs. Indeed executive remuneration is often based on surveys that do not contain criteria like age, experience, education. Llense (2008) for instance finds that CEO compensation is not sensitive to attributes such as age or formal qualification.

${ }^{43}$ The reference degree achieved is a residual category.
} 
those with another major. The location of the firm is also important 44

Beyond trimming, the robustness of the results obtained with the benchmark specification is assessed with respect to a number of other dimensions. In particular, section 5.3 .1 runs the same specification, but where the dependent variable of the second stage is the sum of salary and total wealth, as defined in section 3. Moreover, we check the extent to which the role of links changes when the continuation value simplifies to the salary, as it is the case toward the end of the career. Finally, section 5.3 .2 and 5.3 .3 assess robustness with respect to alternative specifications accounting for the effect of mobility and network size respectively on salary.

\subsection{Characteristics of relevant network components}

This section explores the relevant network components as far as direct and indirect salary effects of links are concerned. In particular, with respect to the rest of a worker's professional network, are colleagues in the contemporaneous firm useful? Moreover, it investigates how the characteristics of links (and in particular duration and age) affect both network direct and indirect relations with salary. That is, are long-lasting or old links more or less useful than short and recent ties?

We consider the role played by contemporaneous colleagues and find evidence confirming the intuition that it is people you know outside your current firm that are more likely to be valuable 45 Indeed, colleagues are not very likely to know much more than the worker herself about other job possibilities, so that, as far as information diffusion is concerned, the relevant employment network does not include worker's colleagues contemporaneous to her mobility decision. Moreover, as far as the direct effect of links on salary is concerned, the most valuable links to the employer are those beyond current and former workers of the firm. ${ }^{46}$ Indeed, the

\footnotetext{
${ }^{44}$ Firms based in the US pay lower salaries. This result may be reconciled with the literature on executive compensation, since Murphy 1999] says that in US CEOs, and not executives in general, are paid more than elsewhere. Moreover, executives working in the US have a larger fraction of their compensation in stock options. Notice also that the dummies indicating firms located in Germany and France are dropped due to collinearity.

${ }^{45}$ Our results, available upon request, are consistent with Geletkanycz et al. 2001 finding that executive external networks are strategically valuable to firms.

${ }^{46}$ Notice that the wage effect of the component of the employment network that is useful because it spreads information and the one that is valuable to the employer tend to empirically coincide for people with low mobility. The reason is that empirically we proxy current and former workers of the firm with the current ones. However, in theory the two components are different. Indeed, former colleagues that left the firm where the individual still works are potentially very useful for spreading original information, while they are not valuable for the employer, since those are redundant links being shared by many employees. From an empirical point of view, it is not easy to assess the number of former colleagues that moved. For instance the number of colleagues may have not changed
} 
latter ones represent quite useless ties for the employer in $t+1$, since they are redundant contacts among workers in the firm.

An interesting issue is how the characteristics of a worker's network influence its direct and indirect effects on the career. The first question is whether the time spent as colleagues plays a role on the usefulness of the tie. In order to answer this question we include in the benchmark specification the average overlap of links in each worker's professional network. This variable captures the average duration of the potentially active link. Indeed, it is very likely that two persons have opportunities of contact when they work as top executives in the same firm, while we cannot be sure whether nodes keep in touch when they do not work together anymore. The average overlap period of network links represents the closest proxy that is available to tie strength in our dataset. The first two columns of table 6 show that networks characterized by longer overlaps are less useful. First, they are not the best channel for spreading information about better opportunities. This result is in line with Granovetter's classical 'strength of weak ties' argument. Second, they have a lower direct effect on salary. In a sense, it is really the size of the network that matters.

Another interesting question is whether the recentness of links impacts their direct and indirect effect on salary. Indeed, it is not straightforward whether more recent links should be more or less useful to get information about job opportunities or more or less valuable for an employer. In order to answer this question we run a variation of the benchmark specification where we include a variable accounting for the average age of workers' links. The estimated coefficient of the network average age in the first stage estimation (third column of table 6) suggests that the time elapsed since nodes were colleagues does not significantly affect their value as information channels. A different conclusion is suggested by the second stage estimation (last column of table 6). Indeed, networks characterized by older links are less valuable as far as their direct effect on salary is concerned.

It would be very interesting to assess the role played by a more precise measure of link tightness. The information available unfortunately does not indicate the intensity of relationships. However, notice that the strength of a link is somehow a subjective matter and two

between $t$ and $t+1$, but just because newcomers compensate workers that left. In a more sophisticated analysis where each node in the network is characterized by its full employment history this distinction is empirically relevant. 
Table 6: The role of link overlap and age (2SLS estimation).

\begin{tabular}{|c|c|c|c|c|}
\hline & \multicolumn{2}{|c|}{ Link Overlap } & \multicolumn{2}{|c|}{ Link Age } \\
\hline & [I stage] & [II stage] & [I stage] & [II stage] \\
\hline & Changed firm & Ln salary & Changed firm & Ln salary \\
\hline \multirow[t]{2}{*}{ Ln links (2002) } & $0.018^{* * *}$ & $0.071^{* * *}$ & $0.019^{* * *}$ & $0.103^{* * *}$ \\
\hline & $(0.00)$ & $(0.01)$ & $(0.00)$ & $(0.02)$ \\
\hline \multirow[t]{2}{*}{ Mean overlap of network links (2002) } & $-0.003^{* *}$ & $-0.011^{* * *}$ & & \\
\hline & $(0.00)$ & $(0.00)$ & & \\
\hline \multirow[t]{2}{*}{ Mean age of network links (2002) } & & & 0.000 & $-0.012^{* * *}$ \\
\hline & & & $(0.00)$ & $(0.00)$ \\
\hline \multirow[t]{2}{*}{ Ln salary $(2002)$} & $-0.015^{* * *}$ & $0.704^{* * *}$ & $-0.015^{* * *}$ & $0.700^{* * *}$ \\
\hline & $(0.00)$ & $(0.02)$ & $(0.00)$ & $(0.02)$ \\
\hline \multirow[t]{2}{*}{ Age (2006) } & -0.000 & 0.022 & -0.000 & 0.024 \\
\hline & $(0.00)$ & $(0.02)$ & $(0.00)$ & $(0.02)$ \\
\hline \multirow[t]{2}{*}{ Age sq. (2006) } & -0.000 & $-0.000^{*}$ & -0.000 & $-0.000^{*}$ \\
\hline & $(0.00)$ & $(0.00)$ & $(0.00)$ & $(0.00)$ \\
\hline \multirow[t]{2}{*}{ Gender: female } & -0.011 & -0.052 & -0.011 & $-0.058^{*}$ \\
\hline & $(0.01)$ & $(0.03)$ & $(0.01)$ & $(0.03)$ \\
\hline \multirow[t]{2}{*}{ Achieved degree: BA } & $0.013^{* *}$ & $0.079^{* * *}$ & $0.014^{* *}$ & $0.083^{* * *}$ \\
\hline & $(0.01)$ & $(0.02)$ & $(0.01)$ & $(0.02)$ \\
\hline \multirow[t]{2}{*}{ Achieved degree: MA } & 0.014 & $0.094^{* * *}$ & $0.016^{*}$ & $0.097^{* * *}$ \\
\hline & $(0.01)$ & $(0.03)$ & $(0.01)$ & $(0.03)$ \\
\hline \multirow[t]{2}{*}{ Achieved degree: $\mathrm{PhD}$} & 0.009 & 0.039 & 0.009 & $0.048^{*}$ \\
\hline & $(0.01)$ & $(0.03)$ & $(0.01)$ & $(0.03)$ \\
\hline \multirow[t]{2}{*}{ Degree major: Business } & $0.018^{* *}$ & $0.047^{*}$ & $0.019^{* *}$ & $0.045^{*}$ \\
\hline & $(0.01)$ & $(0.03)$ & $(0.01)$ & $(0.03)$ \\
\hline \multirow[t]{2}{*}{ Degree major: Finance } & 0.012 & 0.047 & 0.012 & $0.065^{*}$ \\
\hline & $(0.01)$ & $(0.03)$ & $(0.01)$ & $(0.03)$ \\
\hline \multirow[t]{2}{*}{ Degree major: Science } & -0.010 & -0.038 & -0.010 & -0.040 \\
\hline & $(0.02)$ & $(0.07)$ & $(0.02)$ & $(0.07)$ \\
\hline \multirow[t]{2}{*}{ Degree major: Social Sciences } & 0.003 & 0.055 & 0.003 & 0.039 \\
\hline & $(0.01)$ & $(0.05)$ & $(0.01)$ & $(0.05)$ \\
\hline \multirow[t]{2}{*}{ Firm country (2006): UK } & $0.029^{* * *}$ & $0.285^{* * *}$ & $0.033^{* * *}$ & $0.317^{* * *}$ \\
\hline & $(0.01)$ & $(0.03)$ & $(0.01)$ & $(0.03)$ \\
\hline \multirow[t]{2}{*}{ Sectoral growth for 2002-firm (2006-02) } & $-0.025^{*}$ & & $-0.026^{*}$ & \\
\hline & $(0.01)$ & & $(0.01)$ & \\
\hline \multirow[t]{2}{*}{ Headquarters country changed (2006-02) } & $0.560^{* * *}$ & & $0.562^{* * *}$ & \\
\hline & $(0.13)$ & & $(0.13)$ & \\
\hline \multirow[t]{2}{*}{ Changed firm (2002-06) } & & -0.801 & & -0.813 \\
\hline & & $(0.51)$ & & $(0.51)$ \\
\hline \multirow[t]{2}{*}{ Intercept } & 0.080 & $1.110^{* * *}$ & 0.067 & $0.932^{* *}$ \\
\hline & $(0.08)$ & $(0.40)$ & $(0.09)$ & $(0.40)$ \\
\hline $\mathrm{N}$ & 4434 & 4434 & 4434 & 4434 \\
\hline Pseudo $R^{2} / R^{2}$ & 0.064 & 0.573 & 0.063 & 0.573 \\
\hline F statistic cluster-robust & 11.05 & & 11.31 & \\
\hline Hansen J statistic & & 1.478 & & 1.360 \\
\hline Hansen $\mathrm{J} \chi^{2} \mathrm{p}$-value & & 0.224 & & 0.244 \\
\hline
\end{tabular}

Note: Robust Standard Errors in brackets, clustered by firm. Significance levels: *: $10 \%$ **: $5 \%$ ***: $1 \%$. 
persons in a relationship may have a different view on the intensity of their relationship, while we exploit objective characteristics of links. Our measures of link overlap and age avoid the inconsistencies that arise in studies based on subjective reporting on tightness depending on whether the network is considered undirected (i.e. links are bilateral) or directed (i.e. at least a pair of connected nodes is asymmetric in the sense that one directed link is not symmetrically reciprocated).

\subsection{Robustness checks}

\subsubsection{Alternative specifications for continuation value}

While executives in practice devote substantial attention to salary (see section 3), the crucial variable of interest in the dynamic maximization sketched in the theoretical framework is the expected value over the career. The richness of the information available allows us to test the robustness of our results with respect to a different measure of value.

The first two columns of table 7 report the first and second stage estimates of a variation of the benchmark specification where the dependent variable salary is replaced by total wealth 47 The idea is that the sum shares, stock options, and long term incentive programs held in theory approximates better than salary alone the expected value over the career.

The indirect effect of network size on career value through mobility is the same as the indirect effect on salary. However, the second stage estimated elasticity of career value with respect to links is more than four times the one of salary. Therefore, the direct effect of professional links on salary is a very conservative estimate of the value attributed by employers to social capital, especially in the case of the top management of firms, that are the most likely to earn conspicuous total wealth.

A further test of the robustness of our results consists in verifying the extent to which the role of links changes when the continuation value simplifies to the salary, as is the case toward the end of the career. For people over 60 years old the future expected value has a limited role in the optimal value, since the time horizon is short. Therefore, looking at the interaction between the role of links and the fact of being toward the end of the career allows us to disentangle the

\footnotetext{
${ }^{47}$ In order to retain the same sample size, we substitute missing values of total wealth with the mean value for the whole sample.
} 
Table 7: Robustness of network effects to alternative specifications for continuation value (2SLS estimation).

\begin{tabular}{|c|c|c|c|c|}
\hline & $\begin{array}{l}\text { [I stage] } \\
\text { Changed firm }\end{array}$ & $\begin{array}{l}\text { [II stage] } \\
\text { Ln wealth }\end{array}$ & $\begin{array}{l}\text { [I stage] } \\
\text { Changed firm }\end{array}$ & $\begin{array}{l}\text { [II stage] } \\
\text { Ln salary }\end{array}$ \\
\hline Ln links (2002) & $0.019^{* * *}$ & $0.258^{* * *}$ & $0.020^{* * *}$ & $0.078^{* * *}$ \\
\hline & $(0.00)$ & $(0.03)$ & $(0.00)$ & $(0.01)$ \\
\hline Age over 60 (2002) & & & $0.052^{* *}$ & -0.008 \\
\hline Interaction age over $60 \&$ ln links (2002) & & & $\begin{array}{l}-0.013^{* *} \\
(0.01)\end{array}$ & $\begin{array}{l}-0.043 \\
(0.05)\end{array}$ \\
\hline Ln salary $(2002)$ & $\begin{array}{l}-0.015^{\text {*** }} \\
(0.00)\end{array}$ & $\begin{array}{l}0.909 * * * \\
(0.05)\end{array}$ & $\begin{array}{l}-0.015^{* * *} \\
(0.00)\end{array}$ & $\begin{array}{l}0.700^{* * *} \\
(0.02)\end{array}$ \\
\hline Age (2006) & $\begin{array}{l}-0.000 \\
(0.00)\end{array}$ & $\begin{array}{l}-0.131^{* * *} \\
(0.04)\end{array}$ & $\begin{array}{l}-0.000 \\
(0.00)\end{array}$ & $\begin{array}{l}-0.000 \\
(0.02)\end{array}$ \\
\hline Age sq. (2006) & $\begin{array}{l}-0.000 \\
(0.00)\end{array}$ & $\begin{array}{l}0.001^{* * *} \\
(0.00)\end{array}$ & $\begin{array}{l}-0.000 \\
(0.00)\end{array}$ & $\begin{array}{l}-0.000 \\
(0.00)\end{array}$ \\
\hline Gender: female & $\begin{array}{l}-0.011 \\
(0.01)\end{array}$ & $\begin{array}{l}-0.215^{* *} \\
(0.10)\end{array}$ & $\begin{array}{l}-0.011 \\
(0.01)\end{array}$ & $\begin{array}{l}-0.053 \\
(0.03)\end{array}$ \\
\hline Achieved degree: BA & $\begin{array}{l}0.014^{*} \\
(0.01)\end{array}$ & $\begin{array}{l}0.183^{* *} \\
(0.07)\end{array}$ & $\begin{array}{l}0.014^{* *} \\
(0.01)\end{array}$ & $\begin{array}{l}0.083^{* * *} \\
(0.02)\end{array}$ \\
\hline Achieved degree: MA & $\begin{array}{l}0.016^{*} \\
(0.01)\end{array}$ & $\begin{array}{l}0.247^{* * *} \\
(0.08)\end{array}$ & $\begin{array}{l}0.016^{*} \\
(0.01)\end{array}$ & $\begin{array}{l}0.097^{* * *} \\
(0.03)\end{array}$ \\
\hline Achieved degree: $\mathrm{PhD}$ & $\begin{array}{l}0.009 \\
(0.01)\end{array}$ & $\begin{array}{l}0.047 \\
(0.09)\end{array}$ & $\begin{array}{l}0.010 \\
(0.01)\end{array}$ & $\begin{array}{l}0.039 \\
(0.03)\end{array}$ \\
\hline Degree major: Business & $\begin{array}{l}0.019^{* *} \\
(0.01)\end{array}$ & $\begin{array}{l}0.108 \\
(0.07)\end{array}$ & $\begin{array}{l}0.018^{* *} \\
(0.01)\end{array}$ & $\begin{array}{l}0.049^{*} \\
(0.03)\end{array}$ \\
\hline Degree major: Finance & $\begin{array}{l}0.012 \\
(0.01)\end{array}$ & $\begin{array}{l}-0.163^{*} \\
(0.09)\end{array}$ & $\begin{array}{l}0.012 \\
(0.01)\end{array}$ & $\begin{array}{l}0.051 \\
(0.03)\end{array}$ \\
\hline Degree major: Science & $\begin{array}{l}-0.010 \\
(0.02)\end{array}$ & $\begin{array}{l}0.041 \\
(0.20)\end{array}$ & $\begin{array}{l}-0.010 \\
(0.02)\end{array}$ & $\begin{array}{l}-0.033 \\
(0.07)\end{array}$ \\
\hline Degree major: Social Sciences & $\begin{array}{l}0.003 \\
(0.01)\end{array}$ & $\begin{array}{l}0.208^{*} \\
(0.11)\end{array}$ & $\begin{array}{l}0.003 \\
(0.01)\end{array}$ & $\begin{array}{l}0.058 \\
(0.05)\end{array}$ \\
\hline Firm country (2006): UK & $\begin{array}{l}0.033^{* * * *} \\
(0.01)\end{array}$ & $\begin{array}{l}-0.650^{* * *} \\
(0.08)\end{array}$ & $\begin{array}{l}0.032^{* * *} \\
(0.01)\end{array}$ & $\begin{array}{l}0.298^{* * *} \\
(0.03)\end{array}$ \\
\hline Sectoral growth for 2002-firm (2006-02) & $\begin{array}{l}-0.026^{* *} \\
(0.01)\end{array}$ & & $\begin{array}{l}-0.026^{*} \\
(0.01)\end{array}$ & \\
\hline Headquarters country changed (2006-02) & $\begin{array}{l}0.562^{* * *} \\
(0.04)\end{array}$ & & $\begin{array}{l}0.562^{* * *} \\
(0.13)\end{array}$ & \\
\hline Changed firm (2002-06) & & $\begin{array}{l}-1.347 \\
(0.84)\end{array}$ & & $\begin{array}{l}-0.782 \\
(0.50)\end{array}$ \\
\hline Intercept & $\begin{array}{l}0.067 \\
(0.09)\end{array}$ & $\begin{array}{l}6.674^{* * *} \\
(0.98)\end{array}$ & $\begin{array}{l}0.067 \\
(0.10)\end{array}$ & $\begin{array}{l}1.584^{* * *} \\
(0.46)\end{array}$ \\
\hline $\mathrm{N}$ & 4431 & 4431 & 4434 & 4434 \\
\hline Pseudo R ${ }^{2} / \mathrm{R}^{2}$ & 0.063 & 0.305 & $\begin{array}{l}0.063 \\
11.18\end{array}$ & 0.575 \\
\hline $\begin{array}{l}\text { F statistic cluster-robust } \\
\text { Hansen J statistic }\end{array}$ & 11.26 & 0.620 & 11.18 & 1.860 \\
\hline Hansen $\mathrm{J} \chi^{2} \mathrm{p}$-value & & 0.431 & & 0.173 \\
\hline
\end{tabular}

Note: Robust Standard Errors in brackets, clustered by firm. Significance levels: *: $10 \%$ **: $5 \%$ ***: $1 \%$. 
direct and indirect effect of employment networks on utility (see expression 6 in the theoretical section).

The estimated coefficient of the interaction between network size and the fact of being over 60 is negative and significantly different from zero in the first stage (third column of table 7). In other words, toward the end of one's career the role of links as channels of diffusion of job opportunities is fading away.

At the same time, the results of the second stage estimation reported in the last column of table 7 show that the direct effect of links on salary is not significantly different for people over 60.

\subsubsection{Alternative econometric specification for mobility endogeneity}

An empirical difficulty in the analysis is the endogeneity of mobility decisions with respect to salary. Indeed, there may exist unobservable variables that affect workers' decision to change job and also their wages. The problem is that if an individual decides to stay we only observe her salary in her current firm, while if the worker decides to move we only observe the best salary she was offered in another firm. Since we never observe the counterfactual wage, we need to take into account potential endogenous selection. In this case the two groups of individuals, those who stay longer in one firm and those who change firm, are not randomly selected. The benchmark specification of this paper relies on instrumental variable estimation. An alternative specification is running a Heckman model (see Heckman 1979]), a sample correction model where selection is determined by a probit model. The model consists then of two equations: a wage regression and a selection equation. The Heckman model is identified not only parametrically through the exclusion restrictions imposed by the researcher, but also non-parametrically through nonlinearities introduced by the selection equation.

In our framework, the Heckman specification would be:

$$
\begin{gathered}
Y_{t+1}=\beta_{0}+\beta_{1} l_{t}+\beta_{2} X_{t+1}+\epsilon_{t+1} \\
M_{t}^{*}=\delta_{0}+\delta_{1} l_{t}+\delta_{2} Z_{t}+\zeta_{t}
\end{gathered}
$$


Table 8: Robustness of network effects on salary to alternative specification for mobility endogeneity (Heckman estimation).

\begin{tabular}{lllll}
\hline \hline & \multicolumn{2}{c}{ Selection } & \multicolumn{3}{c}{ Wage } \\
& \multicolumn{2}{c}{ Changed firm } & \multicolumn{2}{c}{ Ln salary } \\
\hline Ln links (2002) & $0.244^{* * *}$ & $(0.038)$ & $0.157^{* * *}$ & $(0.040)$ \\
Ln salary (2002) & $-0.201^{* * *}$ & $(0.047)$ & $0.223^{* *}$ & $(0.096)$ \\
Age (2006) & 0.058 & $(0.076)$ & 0.000 & $(0.060)$ \\
Age sq. (2006) & -0.001 & $(0.001)$ & 0.000 & $(0.001)$ \\
Gender: female & -0.146 & $(0.181)$ & $0.217^{* *}$ & $(0.100)$ \\
Achieved degree: BA & $0.312^{* *}$ & $(0.134)$ & $0.600^{* * *}$ & $(0.162)$ \\
Achieved degree: MA & $0.345^{* *}$ & $(0.136)$ & $0.527^{* * *}$ & $(0.118)$ \\
Achieved degree: PhD & 0.251 & $(0.161)$ & 0.210 & $(0.143)$ \\
Degree major: Business & $0.296^{* *}$ & $(0.126)$ & -0.050 & $(0.139)$ \\
Degree major: Finance & 0.234 & $(0.171)$ & 0.245 & $(0.184)$ \\
Degree major: Science & -0.158 & $(0.400)$ & -0.003 & $(0.253)$ \\
Degree major: Social Sciences & 0.092 & $(0.211)$ & 0.352 & $(0.230)$ \\
Firm country: UK (2006) & $0.466^{* * *}$ & $(0.102)$ & 0.064 & $(0.119)$ \\
Sectoral growth for 2002-firm (2006-02) & -0.348 & $(0.219)$ & & \\
Headquarters country changed (2006-02) & $2.170^{* * *}$ & $(0.358)$ & & \\
Intercept & $-3.048^{* *}$ & $(1.800)$ & $2.932^{*}$ & $(1.529)$ \\
\hline$\rho$ & & & 0.039 & $(0.155)$ \\
\hline N & & & & 4435 \\
Log-likelihood & & & & -661.841 \\
\hline \hline
\end{tabular}

Note: Robust Standard Errors in brackets, clustered by firm.

Significance levels: *: $10 \% * *: 5 \% * * *: 1 \%$.

The last equation estimates the probability of changing firm and the regressors $Z_{t}$ include all $X_{t+1}$, plus some instruments. The observed dichotomous realization of the latent variable $M_{t}^{*}$ is whether each sampled worker changed job $\left(M_{t}=1\right)$ or not $\left(M_{t}=0\right)$ :

$$
M_{t}= \begin{cases}1 & \text { if } M_{t}^{*}>0 \\ 0 & \text { otherwise }\end{cases}
$$

The main assumption in this case is that $\epsilon_{i}$ and $u_{i}$ have a bivariate normal distribution. The estimated parameter $\rho$ is the correlation between unobserved determinants of wage and of changing job.

We report the estimation results of a simplified Heckman model with a wage regression and a selection equation 48 The first part of table 8 reports the estimated selection equation,

\footnotetext{
${ }^{48}$ Estimates of the three equations corresponding to the endogenous switching model are available upon request.
} 
while the second part the estimated wage regression!49 The correlation between the residual of the selection and of the wage equation is not significant, suggesting that selection is not endogenous 50 In other words, mobility does not significantly affect salary beyond the channels we control for, as the instrumental variable estimation indicated, too. The indirect impact of links through mobility is highly significant and their direct effect is larger than the instrumental variable estimates. The elasticity of salary with respect to professional links suggested by the estimation of the Heckman model is $0.157 \%$.

\subsubsection{Alternative specifications for unobserved heterogeneity}

The benchmark specification of this paper controls for unobserved heterogeneity mainly through the inclusion of previous salary as a regressor. Another possible approach is to include more controls, namely to control as much as possible for firm characteristics. Indeed, links may be endogenous with respect to salary because they both depend on some firm characteristics.

The second column of table 9 shows that salary indeed depends, beyond the Mincerian determinants, on some characteristics of the firm. Beyond location, $\underset{51}{5}$ firm sector affects salaries in a few cases, once firm size is controlled for ${ }^{52}$ As expected, we find that salary adjusts for company size 53 The estimated elasticity of salary with respect to links is higher than when controlling for past salary. Therefore, our benchmark specification may actually absorb even too much of the individual heterogeneity and it represents a conservative estimate of the network effects. The estimated marginal effect of network on the probability of changing firm reported

\footnotetext{
We also run a censored regression with varying censoring values. Indeed, if we assume that workers change job only if the offered wage is higher than what they could expect in their current firm and otherwise stay in their firm, then salaries of workers who changed job can be interpreted as left censored. That is, their salary would have been less than or equal to the one we observe. Estimates are available upon request. While this approach does rely on the validity of instruments, the Heckman model is more general, allowing the selection between staying in the current job and changing firm to depend not only on standard wage determinants, but also on unobserved factors.

${ }^{49}$ Results are obtained by FIML simultaneous estimation of the two equations.

${ }^{50}$ Similarly, Abowd et al. 2006 find no clear relation between residuals of mobility and wage equation.

${ }^{51}$ See section 5.1 .

${ }^{52}$ Without controlling for size, a few more sectors are significant. The relatively limited importance of sector is not too surprising, since surveys adjust for company size and only sometimes for industry (see Murphy 1999]).

${ }^{53} \mathrm{As}$ often the case, the adjustment appears to be consistent with a simple log-linear regression of logarithm of salary on logarithm of firm size (see Murphy [1999]). Some standard explanations for the relation between firm size and salaries are that monitoring is more difficult in big firms (Bulow and Summers 1976]) and that large firms better select on unobserved worker characteristics (Weiss and Landau 1984]). See Abowd et al. 1999. for a discussion of the firm-size wage effect. Base salary for CEO is typically determined through competitive benchmarking based primarily on general industry salary surveys. Size adjustment in the survey instruments both formalize and reinforce the observed relation between compensation and company size.
} 
Table 9: Robustness of network effects to alternative specifications for unobserved heterogeneity: firm characteristics (2SLS estimation).

\begin{tabular}{|c|c|c|c|c|}
\hline \multirow{2}{*}{$\begin{array}{l}\text { Ln links (2002) } \\
\end{array}$} & \multicolumn{2}{|c|}{$\begin{array}{c}\text { [I stage] } \\
\text { Changed firm }\end{array}$} & \multicolumn{2}{|c|}{$\begin{array}{l}\text { [II stage }] \\
\text { Ln salary }\end{array}$} \\
\hline & $0.017^{* * *}$ & $(0.00)$ & $0.104^{* * *}$ & $(0.01)$ \\
\hline Age (2006) & -0.003 & $(0.00)$ & $0.129 * * *$ & $(0.02)$ \\
\hline Age sq. (2006) & 0.000 & $(0.00)$ & $-0.001^{* * *}$ & $(0.00)$ \\
\hline Gender: female & -0.010 & $(0.01)$ & $-0.216^{* * *}$ & $(0.06)$ \\
\hline Achieved degree: BA & $0.013^{*}$ & $(0.01)$ & $0.182^{* * *}$ & $(0.03)$ \\
\hline Achieved degree: MA & $0.016^{*}$ & $(0.01)$ & $0.183^{* * *}$ & $(0.04)$ \\
\hline Achieved degree: $\mathrm{PhD}$ & 0.010 & $(0.01)$ & $0.195^{* * *}$ & $(0.04)$ \\
\hline Degree major: Business & $0.019^{* *}$ & $(0.01)$ & $0.101^{* * *}$ & $(0.03)$ \\
\hline Degree major: Finance & 0.017 & $(0.01)$ & 0.047 & $(0.04)$ \\
\hline Degree major: Science & -0.008 & $(0.02)$ & 0.004 & $(0.11)$ \\
\hline Degree major: Social Sciences & 0.005 & $(0.01)$ & -0.080 & $(0.06)$ \\
\hline Firm country (2006): UK & $0.033^{* * *}$ & $(0.01)$ & $0.316^{* * *}$ & $(0.03)$ \\
\hline Sector (2006): construction & 0.010 & $(0.01)$ & 0.039 & $(0.06)$ \\
\hline Sector (2006): defense & -0.020 & $(0.02)$ & 0.091 & $(0.07)$ \\
\hline Sector (2006): education & $-0.037^{* *}$ & $(0.02)$ & -0.036 & $(0.08)$ \\
\hline Sector (2006): financial & -0.007 & $(0.01)$ & -0.034 & $(0.05)$ \\
\hline Sector (2006): health & 0.017 & $(0.02)$ & -0.009 & $(0.05)$ \\
\hline Sector (2006): information & 0.008 & $(0.01)$ & 0.022 & $(0.04)$ \\
\hline Sector (2006): mining & 0.019 & $(0.02)$ & $0.157^{* * *}$ & $(0.04)$ \\
\hline Sector $(2006)$ : real estate & 0.010 & $(0.02)$ & $0.241^{* * *}$ & $(0.07)$ \\
\hline Sector $(2006):$ services & 0.005 & $(0.01)$ & $-0.077^{*}$ & $(0.05)$ \\
\hline Sector (2006): technical & 0.022 & $(0.02)$ & $-0.100 *$ & $(0.06)$ \\
\hline Sector (2006): trade & $0.044^{* *}$ & $(0.02)$ & -0.031 & $(0.06)$ \\
\hline Sector (2006): transportation & -0.004 & $(0.01)$ & $-0.172^{* *}$ & $(0.07)$ \\
\hline Sector (2006): utilities & 0.011 & $(0.02)$ & 0.004 & $(0.06)$ \\
\hline Ln firm number of employees (2006) & -0.001 & $(0.00)$ & $0.136^{* * *}$ & $(0.01)$ \\
\hline Sectoral growth for 2002-firm (2006-02) & -0.039 & $(0.03)$ & & \\
\hline Headquarters country changed (2006-02) & $0.557^{* * *}$ & $(0.13)$ & & \\
\hline Changed firm (2002-06) & & & -0.286 & $(0.37)$ \\
\hline Intercept & 0.078 & $(0.09)$ & 0.822 & $(0.59)$ \\
\hline $\mathrm{N}$ & 4389 & & 4389 & \\
\hline Pseudo $R^{2} / R^{2}$ & 0.064 & & 0.215 & \\
\hline F statistic cluster-robust & 10.00 & & & \\
\hline Hansen J statistic & & & 12.092 & \\
\hline Hansen $\mathrm{J} \chi^{2} \mathrm{p}$-value & & & 0.001 & \\
\hline
\end{tabular}

Note: Robust Standard Errors in brackets, clustered by firm.

Significance levels: *: $10 \% * *: 5 \% * * *: 1 \%$.

in the first column of table 9 is basically the same as in the benchmark specification.

Another approach to take into account the endogeneity of links, beyond controlling for 
Table 10: Robustness of network effects to alternative specifications for unobserved heterogeneity: endogeneity of mobility and network size (2SLS estimation).

\begin{tabular}{lllllll}
\hline \hline & \multicolumn{2}{c}{ [I stage] } & \multicolumn{2}{c}{ [I stage] } & \multicolumn{2}{c}{ [I stage] } \\
& \multicolumn{2}{c}{ Ln links } & \multicolumn{2}{c}{ Changed firm } & \multicolumn{2}{c}{ Ln salary } \\
\hline Ln links (2002) & & & & & $0.215^{* * *}$ & $(0.07)$ \\
Ln salary (2002) & $0.276^{* * *}$ & $(0.02)$ & $-0.010^{* *}$ & $(0.00)$ & $0.664^{* * *}$ & $(0.03)$ \\
Age (2006) & -0.022 & $(0.02)$ & -0.001 & $(0.00)$ & 0.026 & $(0.02)$ \\
Age sq. (2006) & 0.000 & $(0.00)$ & -0.000 & $(0.00)$ & $-0.000^{*}$ & $(0.00)$ \\
Gender: female & $0.258^{* * *}$ & $(0.08)$ & -0.006 & $(0.01)$ & $-0.090^{* *}$ & $(0.04)$ \\
Achieved degree: BA & $0.381^{* * *}$ & $(0.04)$ & $0.021^{* * *}$ & $(0.01)$ & 0.027 & $(0.04)$ \\
Achieved degree: MA & $0.536^{* * *}$ & $(0.06)$ & $0.027^{* * *}$ & $(0.01)$ & 0.021 & $(0.05)$ \\
Achieved degree: PhD & $0.395^{* * *}$ & $(0.06)$ & $0.018^{*}$ & $(0.01)$ & -0.016 & $(0.04)$ \\
Degree major: Business & $0.186^{* * *}$ & $(0.05)$ & $0.022^{* *}$ & $(0.01)$ & 0.024 & $(0.03)$ \\
Degree major: Finance & $0.789^{* * *}$ & $(0.08)$ & $0.028^{* *}$ & $(0.01)$ & -0.062 & $(0.07)$ \\
Degree major: Science & $-0.228^{*}$ & $(0.13)$ & -0.015 & $(0.02)$ & -0.002 & $(0.07)$ \\
Degree major: Social Sciences & -0.025 & $(0.07)$ & 0.002 & $(0.01)$ & 0.062 & $(0.05)$ \\
Firm country (2006): UK & $-0.225^{* * *}$ & $(0.05)$ & $0.028^{* * *}$ & $(0.01)$ & $0.334^{* * *}$ & $(0.03)$ \\
Sectoral growth & & & & & & \\
$\quad$ for 2002-firm (2006-02) & $-0.201^{* *}$ & $(0.09)$ & $-0.030^{* *}$ & $(0.01)$ & & \\
Headquarters & & & & & & \\
$\quad$ country changed (2006-02) & 0.028 & $(0.19)$ & $0.564^{* * *}$ & $(0.13)$ & & \\
Number of jobs changed $(2002)$ & $0.916^{* * *}$ & $(0.09)$ & -0.009 & $(0.02)$ & & \\
Changed firm (2002-06) & & & & & -0.822 & $(0.50)$ \\
Intercept & $3.105^{* * *}$ & $(0.60)$ & 0.128 & $(0.08)$ & 0.633 & $(0.47)$ \\
\hline N & 4434 & & 4451 & & 4434 & \\
Pseudo R ${ }^{2} / R^{2}$ & 0.168 & & 0.052 & & 0.539 & \\
F statistic cluster-robust & 34.53 & & 8.01 & & & \\
Hansen J statistic & & & & & 0.374 & \\
Hansen J $\chi^{2}$ p-value & & & & & 0.541 & \\
\hline \hline
\end{tabular}

Note: Robust Standard Errors in brackets, clustered by firm. Significance levels: *: $10 \% * *: 5 \% * * *: 1 \%$.

previous salary, is to directly consider network size as endogenous and instrument it (first column of table 10). In order to take into account the potential endogeneity of links and to estimate this first stage, an additional instrument is included, counting how many times the person changed job before $2002 \underline{54}$

The second column of table 10 reports the first stage estimates of the determinants of mobility decisions and the last one the estimated coefficients of the second stage. The elasticity of salary with respect to professional links is positive and significant, consistently with the benchmark estimate. The magnitude of the elasticity is however about three times larger,

\footnotetext{
${ }^{54}$ As intuitive, the more differentiated the experience in different jobs, the larger the network size.
} 
suggesting that an increase in the number of professional links by $50 \%$ (from the average 122 to 183 links) accompanies an increase of salary of 42 thousand USD (from the average 390 thousand to 432 thousand USD). Our benchmark estimate of link direct effect appears therefore as a conservative one with respect to the case where also links are considered as endogenous (see table 11 for a comparison of estimated elasticities of salary with respect to network size).

Table 11: Estimated elasticities of salary with respect to links (link direct effect).

\begin{tabular}{c|lll}
\hline \hline elasticity & estimation & & \\
\hline 0.179 & basic OLS & without mobility and previous salary & (column [I] table 3) \\
0.060 & basic OLS & without mobility & (column [II] table 3) \\
0.177 & basic OLS & without previous salary & (column [II] table 3) \\
0.055 & basic OLS & & (column [IV] table 3) \\
0.076 & benchmark IV & & (III column table 4) \\
0.074 & robustness IV & no trimming & (III column table [5) \\
0.071 & network charact. IV & with link overlap & (II column table 6) \\
0.103 & network charact. IV & with link age & (IV column table 6) \\
0.258 & robustness IV & continuation value (total wealth) & (II column table 77) \\
0.078 & robustness IV & continuation value (end of career) & (IV column table 7) \\
0.157 & robustness Heckman & mobility endogeneity & (III column table 8) \\
0.104 & robustness IV & unobs. heterogeneity (firm charact.) & (III column table 9) \\
0.215 & robustness IV & unobs. heterogeneity (network endog.) & (V column table 10) \\
\hline \hline
\end{tabular}

\section{Conclusions}

This paper emphasizes that the relation between network and labor outcomes is characterized by multiple mechanisms and dynamic coevolution. The most obvious mechanism whereby the characteristics of professional networks affect an individual's career is that they are privileged channels of information diffusion. Indeed, careers are shaped by a succession of mobility decisions. At many points in time during an individual's career, a worker may receive offers and has to decide whether staying in the current firm or changing job. The probability of moving to another firm is likely to be affected by some characteristics of her employment network. In particular, the larger the first degree network of the individual, the higher the probability that she gets exposed to job offers. This is particularly true in the case of top managers and board members. Indeed, these positions are usually filled through head hunting and professional acquaintanceship, rather than through formal advertisement of openings. 
The second way whereby professional networks influence labor outcomes is that they represent a valuable asset in the eyes of an employer $\frac{55}{5 n}$ In particular, the individuals' employment network outside the firm represents a form of social capital that may be useful for the employer and that is thus remunerated.

While professional links affect labor outcomes, at the same time a worker's network is substantially shaped by career choices. Indeed, decisions along the career path shape the development of one's professional network. Career choices and in particular the decision to change job therefore result from a recursive optimization and it is necessary to look at them in a dynamic way.

Therefore, the paper develops a dynamic framework where the utility of a worker is affected by the choices she makes during her career and by the characteristics of her professional network. In particular, the optimal value depends on professional networks directly through current utility to the extent that links are valuable to the employer and indirectly through the effect that they have on mobility decisions.

The empirical analysis finds evidence that professional networks are relevant both because valuable for the employer and because they facilitate job mobility. For instance, based on our benchmark 2SLS estimates, if a worker had 50\% more links than the average (that is, had 61 more links more than the average 122), her annual salary would be 15 thousand USD higher (from an average of 390 to 405 thousand USD) and the probability of moving would increase by $15 \%$ (from an average of $3.2 \%$ to $3.7 \%$ ). These findings are robust to alternative definitions of career value and specifications accounting for mobility and link endogeneity.

We explore a number of network characteristics to see which matter most for the value of links to an individual. We find, unsurprisingly, that current colleagues are not a useful component of a worker's network. Moreover, networks characterized on average by ties between nodes that have been colleagues for a long time have a lower direct and indirect effect on labor outcomes, corroborating the well known arguments of Granovetter [1973] about 'the strength of weak ties'. Finally, the older are the links in an individual's network, the less valuable they are to the employer.

\footnotetext{
${ }^{55}$ Glaeser et al. 2002] define "individual social capital as a person's social characteristics - including social skills, charisma, and the size of his Rolodex - which enables him to reap market and non-market returns from interactions with others".
} 
Further research could shed light on the relation between other characteristics of professional networks and labor outcomes. In particular, a further step of analysis entails the exploitation of the geometric network structure in order, for instance, to understand the relation between a worker's centrality and her labor outcomes. 


\section{References}

Abowd, J. M., F. Kramarz, and D. N. Margolis (1999). High wage workers and high wage firms. Econometrica 67(2), 251-333.

Abowd, J. M., F. Kramarz, and S. Roux (2006). Wages, mobility and firm performance: advantages and insights from using matched worker-firm data. The Economic Journal 116(512), $245-85$.

Arrow, K. J. and R. Borzekowski (2004). Limited network connections and the distribution of wages. Finance and Economics Discussion Series.

Barabási, A. L. (2002). Linked: How Everything is Connected to Everything Else and What it Means for Business, Science, and Everyday Life. Penguin Group.

Bayer, P., S. Ross, and G. Topa (2008). Place of work and place of residence: Informal hiring networks and labor market outcomes. Journal of Political Economy 116(6), 1150-96.

Beaman, L. (2012). Social networks and the dynamics of labor market outcomes: Evidence from refugees resettled in the U.S. Review of Economic Studies 79, 128-61.

Bentolila, S., C. Michelacci, and J. Suarez (2010). Social contacts and occupational choice. Economica 77(305), 20-45.

Berardi, N. (2010). The remains of informality in the formal sector: social networks and wages in Senegal's formal sector. TSE Working Papers.

Boxman, E. A. W., P. M. De Graaf, and H. D. Flap (1991). The impact of social and human capital on the income attainment of Dutch managers. Social Network 13(1), 51-73.

Brown, R., N. Gao, E. Lee, and K. Stathopoulos (2009). What are friends for CEO networks pay and corporate governance. Mimeo.

Bulow, J. and L. Summers (1976). A theory of dual labor markets with applications to industrial policy, discrimination and Keynesian unemployment. Journal of Labor Economics 4, 376-414. 
Burt, R. (1992). Structural Holes: The Social Structure of Competition. Cambridge, MA: Harvard University Press.

Calvó-Armengol, A. and M. O. Jackson (2004). The effects of social networks on employment and inequality. The American Economic Review 94(3), 426-54.

Cingano, F. and A. Rosolia (2012). People i know: Job search and social networks. Journal of Labor Economics 30(2), 291-332.

Coleman, J. (1988). Social capital in the creation of human capital. American Journal of Sociology 94, 95-120.

Conley, T. and G. Topa (2002). Socio-economic distance and spatial patterns in unemployment. Journal of Applied Econometrics 17(4), 303-27.

Corcoran, M. (1980). Most workers find jobs through word of mouth. Monthly Labor Review 103(8), 33-5.

Engelberg, J., P. Gao, and C. Parsons (2012). The value of a rolodex: CEO pay and personal network. The Review of Financial Studies forthcoming.

Friebel, G. and A. Matros (2005, 07). A note on CEO compensation, elimination tournaments and bankruptcy risk. Economics of Governance 6(2), 105-11.

Frydman, C. and D. Jenter (2010). CEO compensation. Annual Review of Financial Economics 102(2), 75-102.

Geletkanycz, M., B. K. Boyd, and S. Finkelstein (2001). The strategic value of CEO external directorate networks: Implications for CEO compensation. Strategic Management Journal 22, $889-98$.

Glaeser, E. L., D. Laibson, and B. Sacerdote (2002). An economic approach to social capital. The Economic Journal 112(483), 437-58.

Granovetter, M. (1973, August). The strength of weak ties. American Journal of Sociology 78, 1360-80. 
Heckman, J. J. (1979, January). Sample selection bias as a specification error. Econometrica $47(1), 153-61$.

Ioannides, Y. M. and L. Loury (2004, December). Job information networks, neighborhood effects, and inequality. Journal of Economic Literature 42, 1056-93.

Ioannides, Y. M. and A. R. Soetevent (2006). Wages and employment in a random social network with arbitrary degree distribution. The American Economic Review 96(2), 270-4.

Jensen, M. C. and K. J. Murphy (1990). Performance pay and top-management incentives. Journal of Political Economy 98(2), 225-264.

Kugler, A. D. (2003). Employee referrals and efficiency wages. Labor Economics 10, 531-56.

Lalanne, M. and P. Seabright (2011). The old boy network: Gender difference in the impact of social networks on remuneration in top executive jobs. TSE Working Papers.

Montgomery, J. (1991). Social networks and labour market outcomes: toward an economic analysis. American Economic Review 81(5), 1408-18.

Munshi, K. (2003). Networks in the modern economy: Mexican migrants in the U.S. labor market. Quarterly Journal of Economics 118(2), 549-97.

Murphy, K. J. (1999). Executive compensation. Handbook of Labor Economics 3(2), 2485-563.

Patacchini, E. and Y. Zenou (2008). Ethnic networks and employment outcomes. IZA Discussion Paper.

Pistaferri, L. (1999). Informal networks in the Italian labor market. Giornale degli Economisti e Annali di Economia 58, 355-75.

Podolny, J. M. and J. N. Baron (1997). Resources and relationships social networks and mobility in the workplace. American Sociological Review 62(5), 673-93.

Rauch, J. E. (2010). Does network theory connect to the rest of us? a review of Matthew O. Jackson's social and economic networks. Journal of Economic Literature 48(4), 980-86. 
Rees, A. (1966). Information networks in labor markets. American Economic Review 56, 55966.

Saloner, G. (1985). Old boy networks as screening mechanism. Journal of Labor Economics 3, $255-67$.

Simon, J. C. and T. Warner (1992, July). Matchmaker, matchmaker: the effect of the old boy networks on job match quality, earnings and tenure. Journal of Labor Economics 10(3), 306-30.

Weiss, A. and H. J. Landau (1984). Wages, hiring standards, and firm size. Journal of Labor Economics 2, 477-99. 